\title{
Submarine landslides and the importance of the initial sediment composition for run-out length and final deposit
}

\author{
Anders Elverhoi • Hedda Breien • Fabio V. De Blasio • \\ Carl B. Harbitz $\cdot$ Matteo Pagliardi
}

Received: 28 April 2010 / Accepted: 2 July 2010 / Published online: 25 July 2010

(C) The Author(s) 2010. This article is published with open access at Springerlink.com

\begin{abstract}
Much remains to understand the dynamic processes during the flow of submarine landslides. A first relevant problem is to explain the extraordinary mobility of submarine landslides, which has no comparison in subaerial mass movement. Another challenging question is the apparent disparity between submarine landslides that remain compact for hundreds of kilometres and those that disintegrate during the flow, finally evolving into turbidity currents. This problem is linked to a central ongoing debate on the relative importance of turbidity currents versus submarine landslides in reshaping the continental margin. Based on three epitomic case studies and on laboratory experiments with artificial debris flows of various composition, we suggest a possible explanation for the disparity between compact and disintegrating landslides, identifying the clay-to-sand ratio as the key control parameter.
\end{abstract}

Responsible editor: John Grue

A. Elverhoi $(\bowtie) \cdot$ F. V. De Blasio

Department of Geosciences, University of Oslo, P.O. Box 1047, Blindern,

0316 Oslo, Norway

e-mail: anders.elverhoi@geo.uio.no

H. Breien • C. B. Harbitz

Norwegian Geotechnical Institute, P.O. Box 3930, Ullevaal Stadion, 0806 Oslo, Norway

\footnotetext{
A. Elverhoi • H. Breien • C. B. Harbitz International Centre for Geohazards, Norwegian Geotechnical Institute, P.O. Box 3930, Ullevaal Stadion, 0806 Oslo, Norway

M. Pagliardi

FLOW-ING s.r.IPza. J.F. Kennedy, 27, 19124 La Spezia (SP), Italy
}

Keywords Submarine debris flows · Submarine landslides $\cdot$ Modelling $\cdot$ Rheology $\cdot$ Hydroplaning

\section{Introduction}

The present understanding of submarine landsliding is somehow unsatisfactory. On one hand, the analysis of the deposits reveals that submarine landslides may acquire extraordinary mobility. On the other hand, although the products of mass movement are easily recognised, the dynamic processes of submarine landsliding have never been observed in full scale. Moreover, in contrast to many subaerial landslides, submarine landslides are not accessible without costly oceanographic surveys. As a consequence, we know surprisingly little about the physical processes capable of transporting thousands of cubic kilometres of sediments for hundreds of kilometres along slopes that are only a fraction of a degree (e.g. Elverhoi et al. 2002; De Blasio et al. 2005; Breien et al. in press). A better understanding of submarine landsliding is also highly relevant for prediction of tsunamis (e.g. Harbitz et al. 1993).

A prime question related to submarine landsliding regards the extraordinary mobility. Run-out ratios (i.e. fall height-totravel distance) may reach values as low as $0.05-0.01$ (De Blasio et al. 2006). This occurs on gentle slopes with inclination less than $1^{\circ}$ in spite of an increased viscous drag and a reduced gravity due to buoyancy compared to subaerial conditions. A second key question is why some landslides remain compact during their flow while others disintegrate substantially, also developing into a bipartite flow with a highand a low-density layer, commonly referred to as a high and a low-density turbidity current (e.g. Mulder and Cochonat 1996). Because of the inaccessibility of submarine mass wasting, the knowledge gained by oceanographic surveys must be supplemented by experiments and numerical 
modelling (e.g. Mohrig et al. 1998; Marr et al. 2001; Ilstad et al. 2004a, b, c; De Blasio et al. 2005; Gauer et al. 2006). Experiments are usually conducted with an artificial mudflow travelling along a flume or a pool, in order to mimic the submarine environment (e.g. Hampton 1972). However, a major problem is that the flow volumes used in the experiments are some $10^{12}$ times smaller than the ones involved in the largest submarine landslides. Numerical models may in principle be calibrated to simulate the small-scale events observed in the laboratory and so extended to large-scale events (Gauer et al. 2006). In spite of their limitations, the laboratory experiments and numerical modelling have shown some intriguing possibilities for explaining mass wasting and indicating directions for further progress.

The purpose of this paper is to use our most recent experimental flume results as background information in order to explain the apparent differences in the behaviour of three full-scale submarine landslides. Emphasis will be given on elucidating how the composition of the initially released masses may have influenced the flow behaviour and final deposition. Two of the landslides are well known and volumetrically huge, i.e. the Holocene Storegga landslide off western Norway (Solheim et al. 2005; Bryn et al. 2005) and the 1929 Grand Banks landslide off Nova Scotia/Newfoundland (e.g. Piper et al. 1999; Fig. 1a, b). In addition we focus on the Bear Island Fan complex, known for its late Pleistocene well-defined and long run-out debris flows (Laberg and Vorren 2000; Marr et al. 2002; Fig. 1a).

It should be noted that in this paper, a debris flow has visco-plastic properties, while we apply the term 'bipartite flow' when the flow becomes completely fluidised and separates into a high- and a low-density layer, both with the properties of a Newtonian fluid (i.e. with zero yield strength). We thus restrict the term 'fluidisation' to a situation where the pore fluids obliterate the effect of particle friction. We also remark that in addition to cohesion, a debris flow may also include a frictional component in the rheology if not fully fluidised. The lowdensity layer corresponds to what is commonly referred to as the turbidity current, where 'turbidity' should refer to a certain low concentration of fine-grained particles in suspension as also proposed by Mulder and Alexander (2001), rather than the common interpretation of a turbulent regime. The high-density layer refers to what is often classified as the 'high-density turbidity current'. However, as discussed below and previously shown by Breien et al. (in press), this high-density layer does not have the commonly described erosive capability as often suggested (e.g. Mulder and Cochonat 1996; Baas et al. 2009).
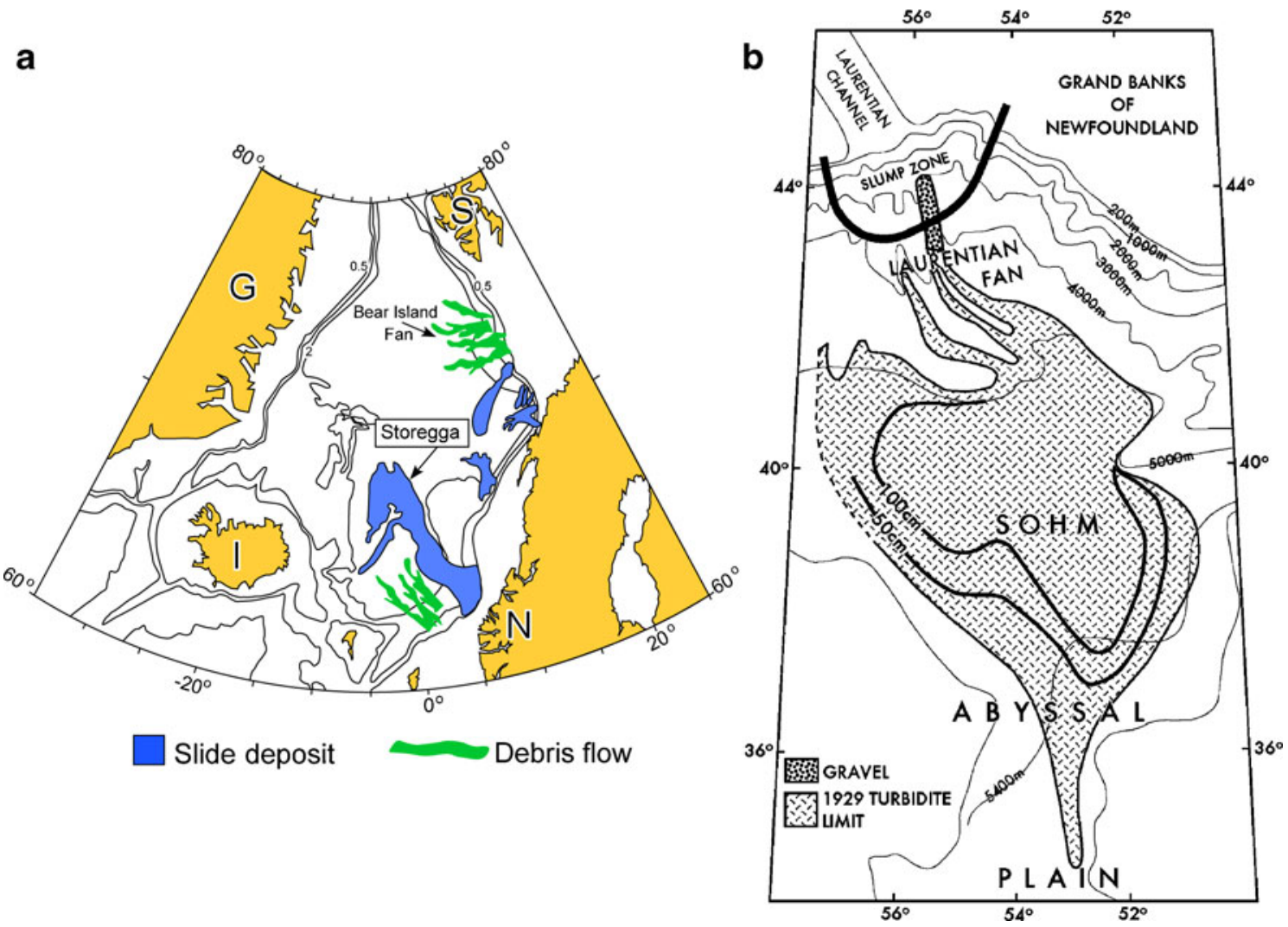

Fig. 1 a Overview map showing Storegga landslide and the Bear Island Fan complex. b Overview map showing the Grand Banks landslide (modified from Piper and Aksu (1987)) 


\section{Case studies}

\subsection{The Bear Island Fan complex}

Extensive landslide activity characterises the huge depocentres beyond the outlet of large ice streams terminating at the Bear Island Fan (Fig. 1a). A significant part of the sediments consists of well-defined debris lobes. The lobes in the uppermost part of these sediments were most likely deposited during the last glacial maximum. They are typically about $30 \mathrm{~m}$ thick and $10 \mathrm{~km}$ wide, and comprised of clay-rich material (Laberg and Vorren 2000; Marr et al. 2002). The astonishing aspect of these debris flows is the enormous travel distance of more than $150 \mathrm{~km}$ despite an average seafloor inclination of only $0.7^{\circ}$, corresponding to a run-out ratio of only 0.012 (e.g. De Blasio et al. 2006). Seafloor mapping and sediment coring reveal rather homogeneous composition along the whole flow path. Moreover, these debris flows do not seem to be associated with distal fine-grained deposits. Thus, they have most likely been formed and travelled down the slope as massive nonfluidized debris flows with a limited (if any) generation of an overriding low-density layer (i.e. a low-density turbidity current, e.g. Hampton 1972). It should also be noticed that a limited amount of erosion or erosional features have been related to the debris flows at the Bear Island Fan complex (e.g. Laberg and Vorren 2000). It is believed that rapid sedimentation in front of an active ice margin, implying sediment instability due to excess pore pressure, may have caused cyclic release of sediments (e.g. Dimakis et al. 2000).

\subsection{The Storegga landslide}

The Norwegian continental margin has demonstrated a broad variety of submarine mass movements, with the 8150 BP Storegga landslide as the most well known and spectacular single landslide identified so far (Vorren et al. 1998; Haflidason et al. 2005; Bryn et al. 2005; Solheim et al. 2005; Sejrup et al. 2005).

The Storegga landslide (Bondevik et al. 2005) is rather complex, comprising numerous individual landslides at different scales with a total volume of about $3,100 \mathrm{~km}^{3}$ (Haflidason et al. 2005). However, the Storegga landslide represents one major event (as opposed to the multi-flow system at the Bear Island Fan) with a first phase travelling more than $400 \mathrm{~km}$ and a termination phase dominated by a series of smaller landslides with significantly shorter travel distances of 10-15 km (Fig. 2). The long travel distance as well as a distal fine-grained deposit of the first phase most likely reflects the material properties of the uppermost sediment layers, while the final short-travelling landslides reflect the well-compacted material at the bottom of the landslide scar (300-400 m head wall; Fig. 2). It is believed

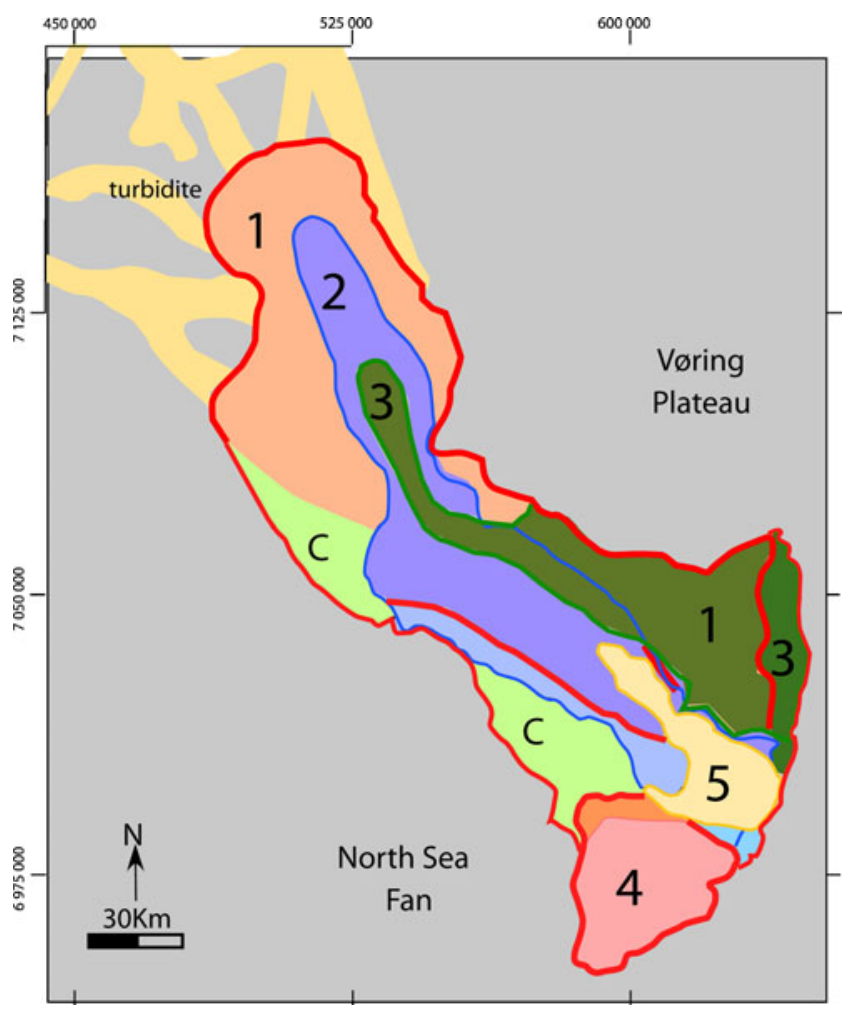

Fig. 2 Main Storegga landslide events (see Fig. 1a) (phases) labelled 1-5. Different colours represent constitutive phases. Phase 1 is shown in red. Phase 1 was followed by retrogressive smaller events (phases 2-5). Light green areas show a compression zone created by the impact (modified from De Blasio et al. (2005))

that the Storegga landslide was triggered by the combination of seismic activity and weak layers (Bryn et al. 2005).

\subsection{The 1929 Grand Banks landslide}

The Grand Banks landslide (Fig. 1b), associated with an earthquake and the breakage of numerous telecables, has provided important information on the flow velocity. The highest recorded velocity of about $28 \mathrm{~m} / \mathrm{s}(\sim 100 \mathrm{~km} / \mathrm{h})$ was reached in the upper part of the continental rise at a water depth of about 4,000 $\mathrm{m}$ (Heezen et al. 1954). Based on extensive seafloor mapping and coring, Piper et al. (1984, 1999) suggest that muddy sediment was released close to the shelf edge as debris flows cascading down the Laurentian Channel. A rough topography leading to a varying flow velocity may have been important for the disintegration and transformation of the debris flows into a turbidity current (according to the terminology of Piper et al. (1999) and Piper and Normark (2009)). Mass balance calculations indicate two sediment sources: fine-grained muddy sediments from the upper continental slope and coarser-grained sand and gravel most likely originating from the valleys of the Laurentian Channel (Piper and Aksu 1987). Limited, or an 
absence of, vigorous erosion related to the mass flow has been reported in some parts of the Grand Bank landslide area (Piper et al. 1999). As with the Bear Island Fan complex and the Storegga landslides, the 1929 Grand Banks landslide largely consists of sediments originally laid down during glaciations. A tentative minimum volume of the Grand Banks landslide is about $185 \mathrm{~km}^{3}$ (Piper and Aksu 1987).

\section{Comparison of the three landslide complexes}

From the above examples, which are all related to glacially influenced continental margins, we notice that mass failure may either lead to a situation with massive debris flows or bipartite flows. The actual situation has a strong influence on the final deposits. In the first situation, muddy massive debris flows are deposited (the Bear Island Fan complex and the Storegga landslides). In contrast, the deposits of the Grand Banks landslide reveal well-defined sand lobes and more distal units of mud and silt. This might indicate disintegration of the debris flow and, as argued below, a possible transformation into a bipartite flow.

\section{Laboratory experiments and sediment composition}

\subsection{Laboratory flume facility}

Flow experiments were performed at the St. Anthony Falls Laboratory, University of Minnesota, in a flume inside a 10-m long, 3-m high and 0.6-m wide tank (Fig. 3). The tank can be filled completely with water and has transparent Plexiglass walls. Inside the tank, the slope of a 0.2-m wide Plexiglass flume is adjusted to the desired inclination by means of wires. The flume bed has a layer of black roof shingle that provides an even degree of roughness of around $1 \mathrm{~mm}$. At the top end of the flume, the debris flow slurry is filled into the head tank, which is opened by a gate mechanism. The gate is operated manually and automatically triggers the data acquisition system. The sediment runs down the inner flume and exits into the large tank at the end. The data acquisition system (Breien 2009) was synchronised, ensuring that all measurement sequences were triggered at the same instant when the gate was opened. The flow was monitored with regular and high-speed video cameras and with pressure transducers.

\subsection{Cameras}

We used high-speed cameras of the type Silicon Video $9 M 001 C$ mounted outside the tank, placed respectively 3.6, 4.1, 7.3 and $7.8 \mathrm{~m}$ from the gate (I-IV in Fig. 3). The experiments were recorded at a frame rate of $240 \mathrm{fps}$. Vertical resolution was set to 600 pixels ( 1 pixel $=1 / 9,000 \mathrm{~m}$ ), giving a horizontal resolution of 200 pixels. Each camera recorded 4,000 frames per experiment, corresponding to $16.5 \mathrm{~s}$. At a velocity of around $1 \mathrm{~m} / \mathrm{s}$, a frame rate of $240 \mathrm{fps}$ would give a displacement of 25 pixels between two consecutive frames. In addition to the high-speed cameras, two standard digitalvideo cameras (PIXCI board cameras) were used to capture the overview (Fig. 3).

A particle image velocimetry (PIV) algorithm (Sveen and Cowen 2004; Pagliardi 2007) applied to the high-speed camera images permitted us to calculate the velocity of the debris flow slurry particles close to the wall. We calculated the velocity field ( $u$ and $v$ components) for each image, i.e. every $0.004 \mathrm{~s}$ and with a spatial resolution of about $1 \mathrm{~mm}$, using cross-correlation methods between two sub-windows. Similar use of PIV can be found for example in Spinewine et al. (2003), Pouliquen (2004) and Barbolini et al. (2005). For subaqueous debris flows, high-speed cameras have also been applied before, but particle tracking was then done manually (Ilstad et al. 2004b).

Fig. 3 Set-up of the experimental flume at St. Anthony Falls Laboratory. $I-I V$ represent high-speed camera positions. Pressure sensors and video cameras were placed between $I$ and $I I$ and between $I I I$ and $I V$. Not to scale, and slope inclination exaggerated

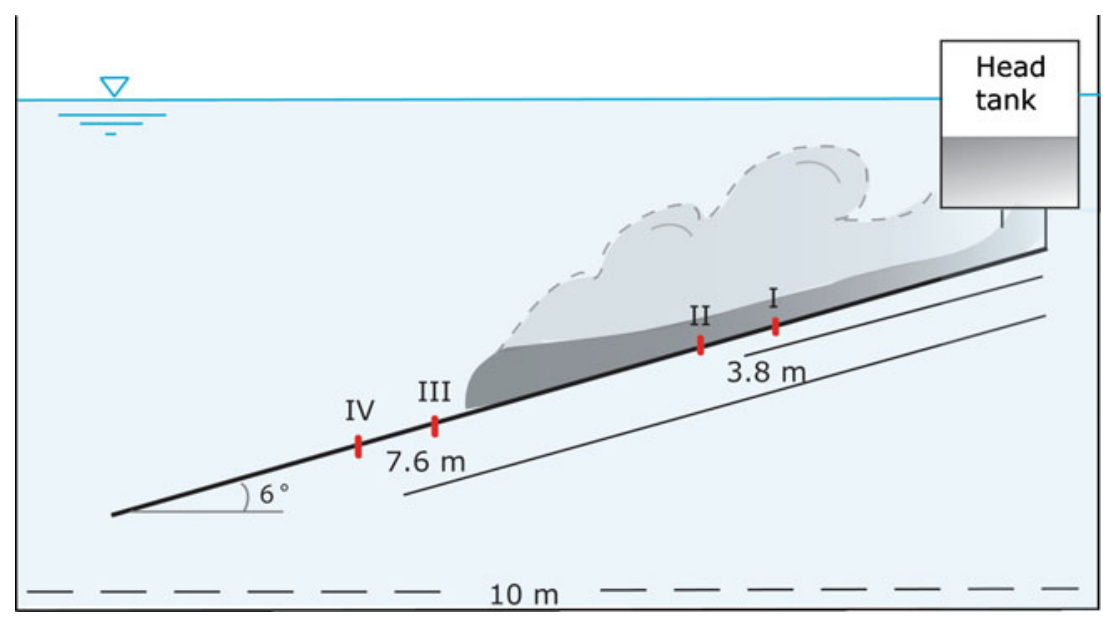




\subsection{Pressure transducers}

Two pairs of porewater pressure and total normal stress sensors were mounted in the bed of the chute, at 3.8 and $7.6 \mathrm{~m}$ from the gate of the head tank. The pressure transducers were mounted flush with the bed. Druck sensors were used to measure the porewater pressure, and Honeywell pressure sensors were used for the total pressure. The pressure measurements were done with reference to the ambient air and therefore affected by barometric changes. For this reason, calibration was performed prior to each set of runs. The pore pressure transducers were flushed out prior to each experiment to expel any air in the tubes and to make sure the filter pores were not clogged.

Pressure and stress distributions provide important information regarding flow behaviour and flow regimes at work. Measurements were attempted at upstream and downstream locations (Fig. 3), but the interpretation was not straightforward. We want to stress these complications to assist others in similar situations. In some cases, measured pore pressures were higher than the total pressure during the experiments. This situation is not physically consistent but was nevertheless observed also in earlier experimental studies (Ilstad et al. 2004a; Major and Iverson 1999). Most likely, the phenomenon is an artefact of the mounting of the measuring system and of clogging of the filters. It may also be due to sediment arching and stress relief over the total stress sensor. Due to these complications, we do not rely on the pressure measurements alone but use the data to support our observations of velocity and possible hydroplaning. Examples of the pressure measurements are shown in Fig. 4. The measurements are complex and most likely affected by the flume set-up and thus require special attention.

The initial wiggles (up to $t=1-2 \mathrm{~s}$ ) in the total stress measurements are flume vibrations triggered by the opening of the gate. A pressure rise of about $200 \mathrm{~Pa}$ (at $t \sim 3 \mathrm{~s}$ ) is due to the release of the 1001 of debris flow slurry from the head tank into the main tank and the resulting increase in water level, before the frontal dynamic pressure arrives. The stress peak (at $t=6-7 \mathrm{~s}$ ) corresponds to the arrival of the debris flow front. As the flow comes to rest, the pore pressure dissipates with time, and the difference between pore and total pressures increases.

\subsection{Sediment composition}

The material used was red flint medium sand (grain-size distribution is given in Fig. 5), white industrial kaolin (Snowbrite) and coal slag (Black Diamond). Kaolin is a low reaction clay of density $2.75 \mathrm{~g} / \mathrm{cm}^{3}$. The sand and coal slag have a density of 2.65 and $2.6 \mathrm{~g} / \mathrm{cm}^{3}$, respectively. Note that in these sets of experiments, no silt-sized materials were included. The reason is that we primarily have focused on how the clay concentration will influence the overall flow behaviour, visco-plastic versus a granular-frictional flow or Newtonian fluid. We also refer to the section on scaling in 'Section 6', 'Section 6.1' and Appendix). Every run contained 5\% coal slag by weight for easier particle tracking. The coal slag is black and easily distinguishable from the reddish sand. The density of the mixed slurries was around $1.8 \mathrm{~g} / \mathrm{cm}^{3}$ at release.

Sand-clay-water mixtures of varying concentrations were used. A range of clay concentrations from 'low' $(5 \%$ and $10 \%$ by weight) via 'medium' ( $15 \%$ by weight) to 'high' ( $20 \%$ and $25 \%$ by weight) was tested, the sand content varying correspondingly whilst the water content was kept constant at $28 \%$ by weight. Clay concentrations less than $5 \%$ did not fulfil the requirement of a homogeneous material as the sand grains settled out immediately and resulted in a bipartite flow from the start. In the following, the slurries are differentiated and referred to by their clay concentration in weight percent (5-25\%). In this paper, we concentrate on the results obtained with the lowest $(5 \%)$, middle $(15 \%)$ and highest $(25 \%)$ clay contents.

Clay and water were mixed in a concrete blender before sand and coal slag were added incrementally, with half a minute of mixing in between each addition. After all the sediments had been added, the blender was left to run for $30 \mathrm{~min}$ to produce a homogeneous, remoulded sediment mixture. Immediately before each flume experiment, 1001 of sediment mixture were loaded into the head tank (Fig. 3). Since the rheology of the mixture is found to be time- and
Fig. 4 a Pore and total pressures in a subaqueous debris flow of $25 \%$ clay. Only the first $15 \mathrm{~s}$ are displayed. b Pore and total pressure measured in a subaqueous debris flow of $5 \%$ clay. Only the first $15 \mathrm{~s}$ are displayed
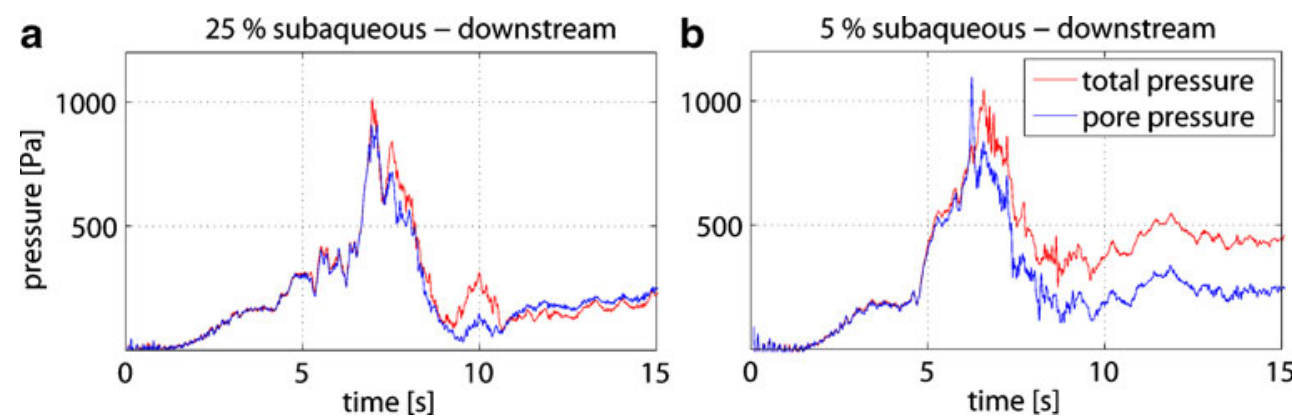


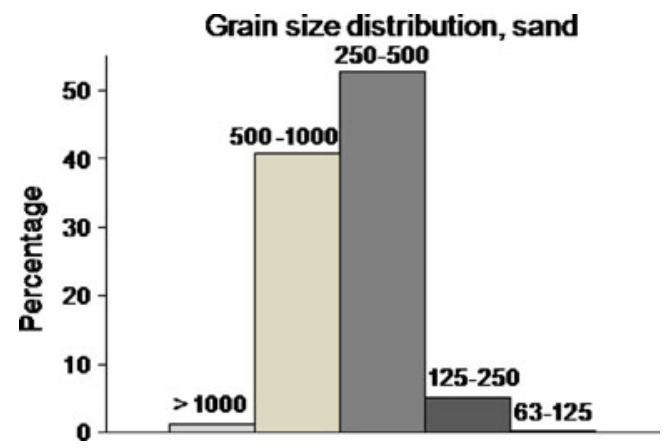

Fig. 5 Grain-size distribution $(\mu \mathrm{m})$ of the red flint sand (medium). Note that there is no silt present

shear rate-dependent, we were careful to spend the same time mixing the debris flow slurry prior to each experiment. However, as seen from the rheometer tests below (Fig. 6), the sediments revealed a certain strength, even at low clay content sufficient to avoid segregation during experiments.

To support our study of debris flow behaviour in the flume and the effect of a variable sand-clay content in the suspension, we used the ball measuring system (BMS) in the Paar Physica modular compact rheometer. This rheometer was also used among others by Sosio et al. (2006) for rheological measurements of natural debris flow material. To assess the applicability of the BMS system, Schatzmann et al. (2003) as well as Si (2007) compared the results of the BMS system with conventional systems, finding the agreement between the flow curves obtained by both systems good. The slurries were found to exhibit a Herschel-Bulkley behaviour (Fig. 6). The slurries are yield strength slurries as they exhibit a finite value at 0 shear rate. If we separately consider the intervals of shear rate $0<\dot{\gamma}<20$ and $\dot{\gamma}>20$, we find a reasonable fit with a Herschel-Bulkley model of the form $\tau=\tau_{\gamma}+\mu \gamma^{\alpha}$, a commonly used rheology for fine-grained (muddy) debris flows (Coussot and Piau 1994; Remaitre et al. 2005). The exponent $\alpha$ changes from $\alpha<1$ (shear-thinning) at lower shear rates (up to at least $20 \mathrm{~s}^{-1}$ ) to $\alpha>1$ (shearthickening) at higher shear rates $\left(>20-100 \mathrm{~s}^{-1}\right)$.

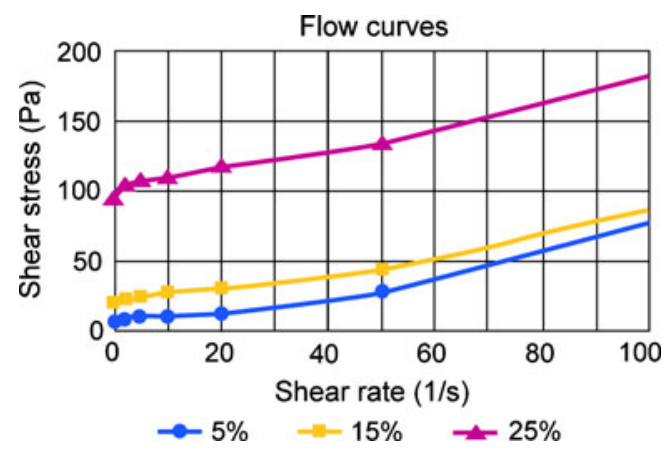

Fig. 6 Flow curves of the different slurries showing shear stress versus shear rate

\section{Experimental results}

Our experiments build on findings from previous flume experiments, such as those by Mohrig et al. (1998); Marr et al. (2001) and Ilstad et al. (2004a, b, c), as well as the pioneering work of Kuenen and Migliorini (1950) and Hampton (1972). We also refer to previous papers by Breien et al. (2007, in press) and Pagliardi (2007) based on the same set of experiments.

\subsection{High clay content (25\%)}

The flows with high clay content $(25 \%$ by weight) are coherent and keep their composition for the duration of the flume flow (Fig. 7). The 25\% debris flow slurry flows easily with a velocity of about $1 \mathrm{~m} / \mathrm{s}$ and shows no sign of deceleration. It leaves almost no sediment behind (Fig. 7). The velocity profiles show a clear plug flow on top of a thin shear zone (Fig. 7c). The frontal snapshot and velocity profile demonstrate marked hydroplaning. The flow moves more or less as a rigid block, and there is a clear demarcation between the body and the head of the flow (in some cases, the two parts are almost separated). The coherency suppresses turbulence and results in only a very small low-density layer; however, Fig. 7c clearly shows that there are two more or less separate layers. As seen from velocity profiles and the colour plot of velocity, throughout the duration of the experiment, the lower high-density layer travels faster than the upper low-density layer.

The velocity vectors and velocity profiles reveal that the dense layer is laminar (also supported by the Reynolds number analysis below). The fulfilment of the conditions for hydroplaning to occur (including the ability to keep the material together) causes a lift of the frontal part of the flow (first $20 \mathrm{~cm}$ ) so that it rides on a cushion of water (hydroplaning, e.g. Mohrig et al. 1998; De Blasio et al. 2004), substantially reducing the basal drag. Equal pore pressure and total stress values throughout the whole flow support that hydroplaning takes place (Fig. 4), as was also observed by Ilstad et al. (2004a).

\subsection{Medium clay content (15\%)}

Decreasing the clay content of the debris flow slurry to $15 \%$ by weight (Fig. 8) implies lower coherency and lower yield strength. Hence, break-up of the flow and formation of a larger low-density layer is easily visible. Break-up and segregation of the flow into a bipartite one with an additional layer of deposition starts at frame 400 (i.e. $1.5 \mathrm{~s}$ behind the front). The front is turbulent, as seen from the upwardpointing velocity vectors and the oscillating velocity (Fig. 8a, b), whilst the body flows in a laminar regime. These visual observations hint at a more transitional flow regime throughout the event. The velocity profiles (Fig. 8c) show 
a
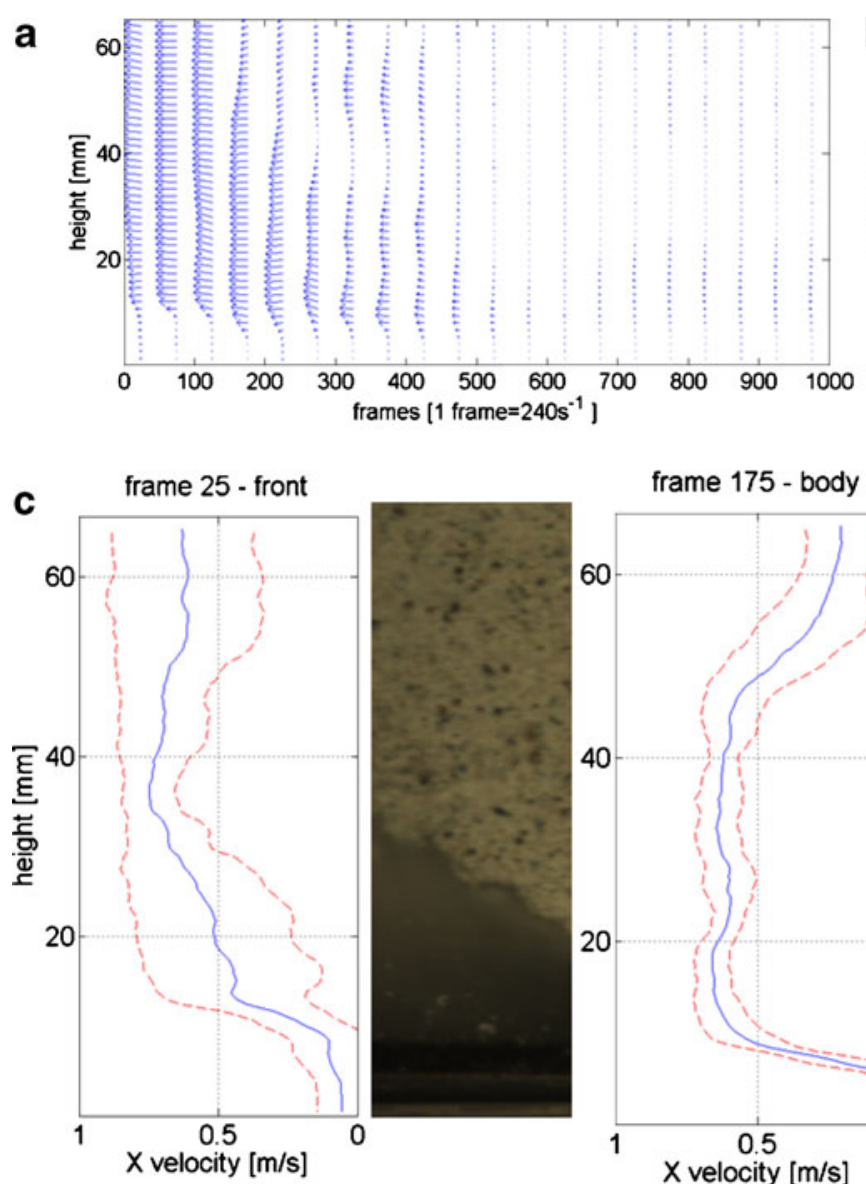

d

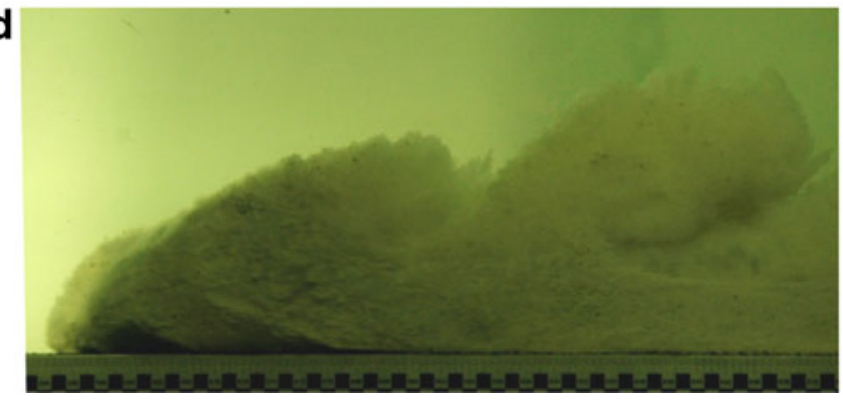

Fig. 7 Data representation of a subaqueous debris flow with $25 \%$ clay. a Vectors showing velocity distribution through time at the upstream station $4.1 \mathrm{~m}$ from the gate. The shear zone is thin, and a clear and large plug flow with a constant velocity (especially in the head) is found on top. Hydroplaning is illustrated by the height of the zero velocity layer at the bottom of the profiles. Negligible deposition on the bed. b Velocity distribution with time, close to the wall (averaged in $x$-direction). The light blue line represents the deposition boundary. Deposition on the bed is negligible. We recognise a pronounced high velocity head and block-like behaviour. c Velocity profiles (blue, solid line) and corresponding photos for head, body and

plug flow towards the tail of the flow, but this is not as clear in the beginning of the flow. Shear and friction along the bed and between grains are far more visible than in more coherent flows, and the shear layer is thicker. This is attributed to the less pronounced hydroplaning (first $10 \mathrm{~cm}$ of the flow) compared to the clay-rich flows. However,
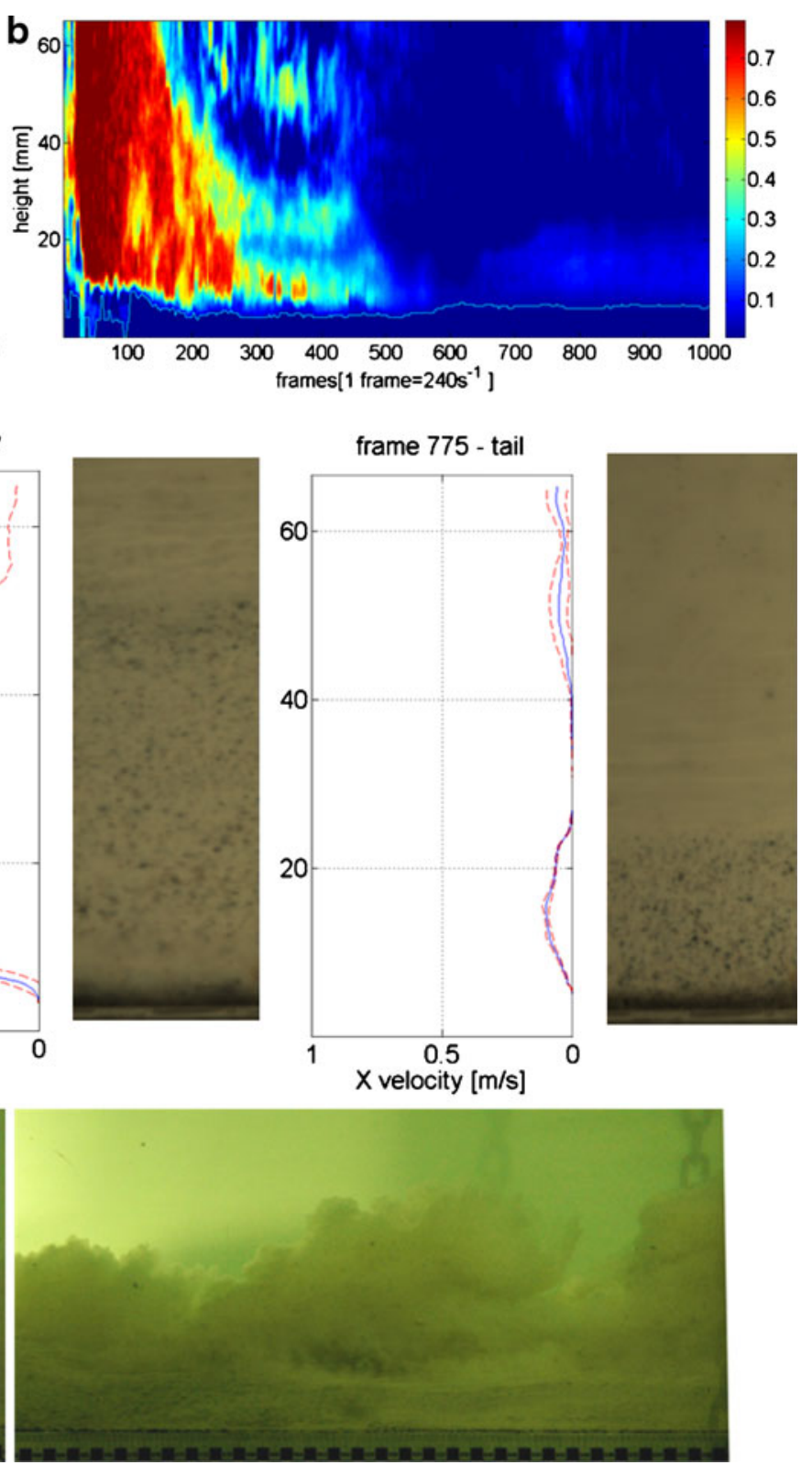

tail of the flow as they pass the upstream station. As is clearly seen from the left photo, the head exhibits pronounced hydroplaning, with a relatively thick water cushion between the debris and the bed. The clay forms a thick and coherent muddy matrix that seems to totally support the well-dispersed sand grains. The velocity profile exhibits a distinct plug flow riding on top of a deformable layer in which the shearing occurs. d Photos: front and body. We see a clear distinction between the laminar flow regime in the lower, dense part of the flow and the upper turbulent turbidity current. Eddies are visible inside the turbidity current

hydroplaning can still be recognised in the pressure measurements. We see that due to the gradual disintegration of the debris flow slurry and its depletion in fines, flow regimes and support mechanisms can radically change during flow and range from matrix support to grain-grain support in originally medium coherent slurries. 

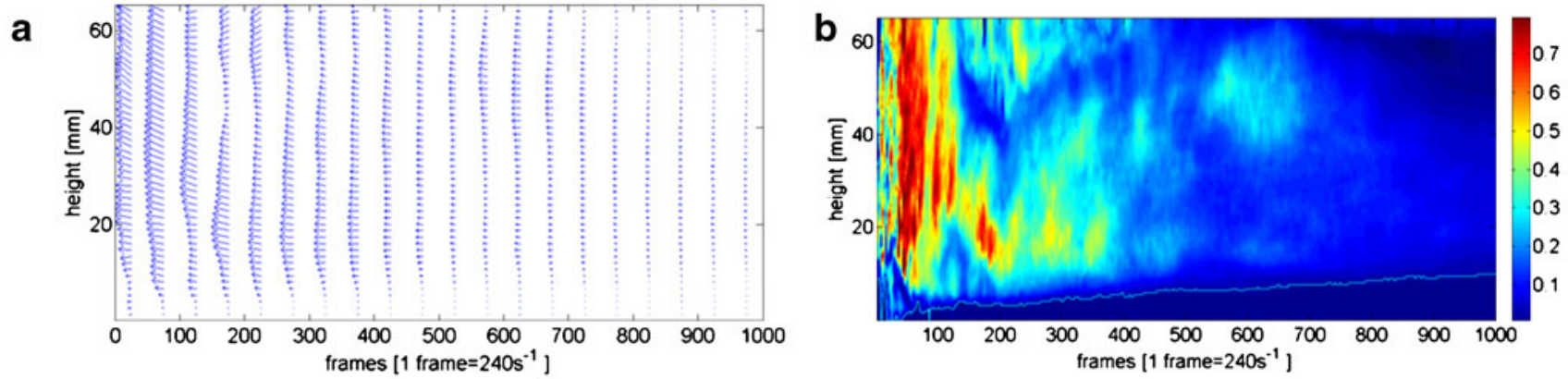

C
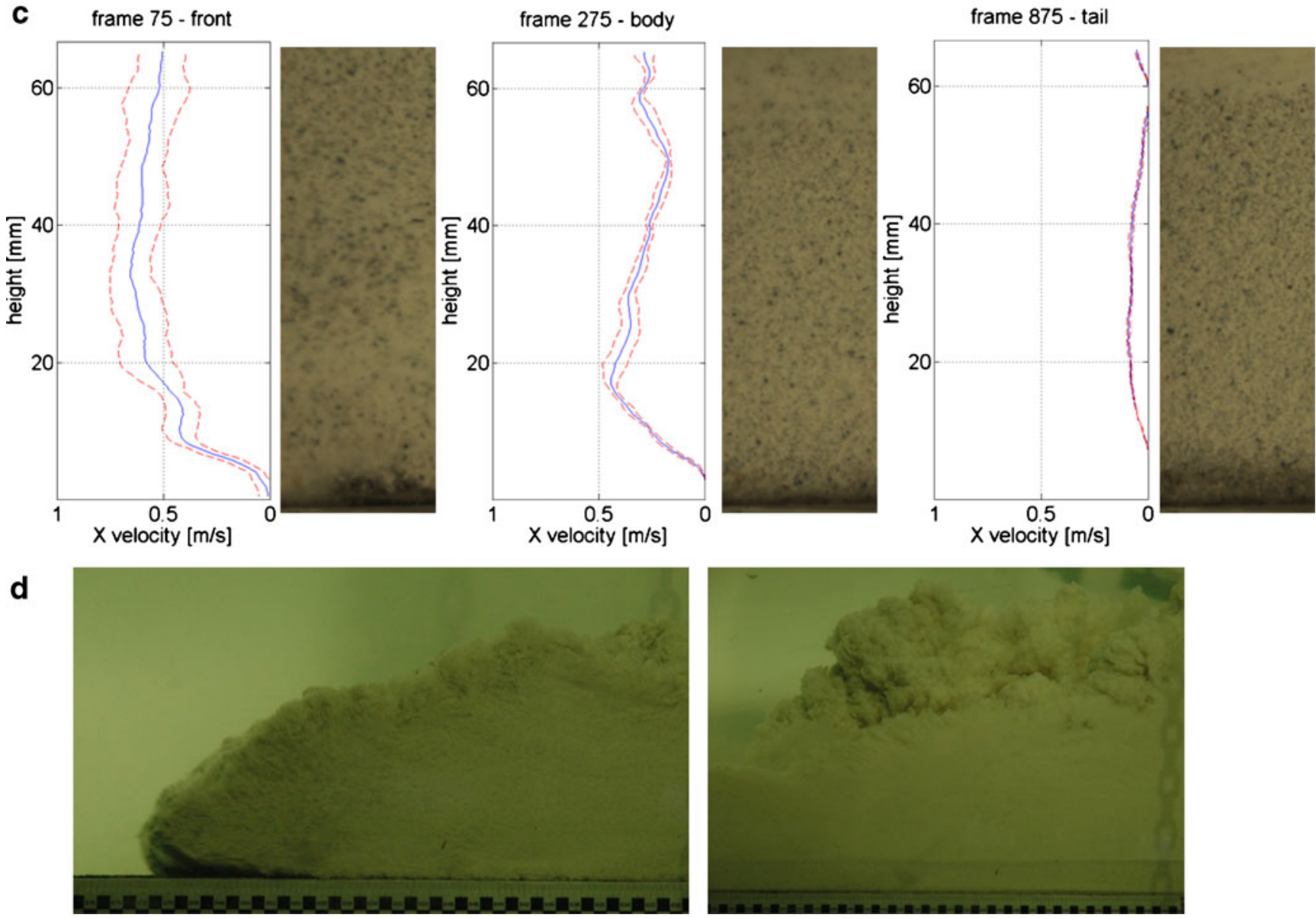

Fig. 8 Data representation of a subaqueous debris flow with $15 \%$ clay content. a Vectors showing velocity distribution through time at the upstream station $4.1 \mathrm{~m}$ from the gate. A clear upward gradient is evident in the head/first 100 frames. b Velocity distribution with time, close to the wall (averaged in $x$-direction). A bipartite flow develops. At the same time, a little deposition starts to occur. $\mathbf{c}$ Velocity profiles

\subsection{Low clay content $(5 \%)$}

The low coherency of the 5\% clay flows results in break-up, turbulence (Fig. 9) and extensive low-density layer production throughout the flow. The transition between lower dense and dilute flow is diffuse and gradual due to the large degree of water incorporation.

A large upward velocity gradient is seen in the frontal parts, and the velocity profile is strongly fluctuating, i.e. (blue, solid line) and corresponding photos for head, body and tail of flow as the flow passes the upstream station. Hydroplaning is still evident. The whole event evolves more slowly than the $25 \%$ clay flow (Fig. 6). d Photos: front, body and tail. We see a clear separation into a lower, sandy layer and an upper, turbidity current

clear indications of turbulence. Incorporation of water, turbulence and segregation lead to effective separation of the grain sizes. The low-density layer consists mostly of clay particles and does not carry much sand.

As a result of the water incorporation and break-up, the flow sprinkles sand on the flume bed as it moves along, continuously losing mass on its way and leaving behind a carpet of sand (Fig. 10). In Fig. 9c, the colour of the deposit near the bed is darker (sandier) than the sand-depleted layer 

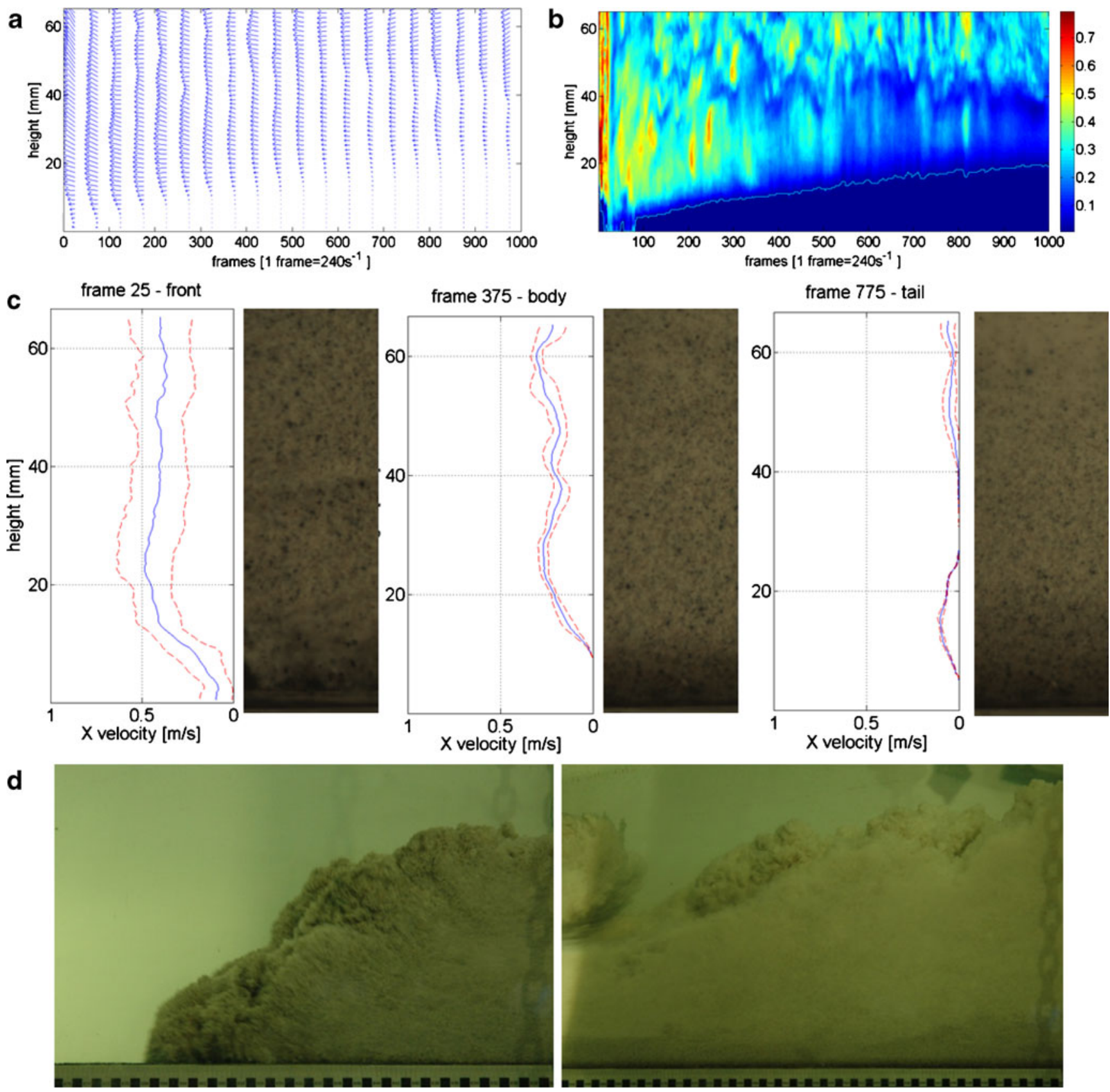

Fig. 9 Data representation of a subaqueous debris flow with 5\% clay content. a Vectors showing velocity distribution through time at the upstream station $4.1 \mathrm{~m}$ from the gate. There is a pronounced upward gradient in the head. Separation between dense flow and turbidity current is very diffuse. After around 6-700 frames, the high-density layer has settled, and it is only the upper low-density layer that moves. b Vectors close to the wall, showing velocity distribution at a distance from the gate through time. A lower general velocity is exhibited, and there is less differentiation in velocity in the horizontal direction than in the more clay-rich slurries. High, constant sedimentation rate. c Velocity

close to the interface with the low-density layer. The velocity profiles are more linear (due to friction) and show a lower high-density layer of more constant velocity which develops into a more dilute low-density layer of similar velocity. A profiles (blue, solid line) and corresponding photos for head, body and tail of flow as it passes the upstream station. Pulsing/wave motion in the lower dense layer might entrain earlier deposited material, as seen by the thinner deposit in the tail frame than the body frame. $\mathbf{d}$ Photos: front and body. The flow seems homogeneous in the first photos, until settling of sand becomes evident. The moving high-density sandy layer is seen in the right photo, with a thick upper low-density layer. Wave motion in the sandy layer and eddies on top of the low-density layer are recognised

larger part of the flow is turbulent, and low-density layer generation is more effective than in the $25 \%$ flow.

In the upper part of the high-density layer, the grains are generally well separated. We suggest that the support 

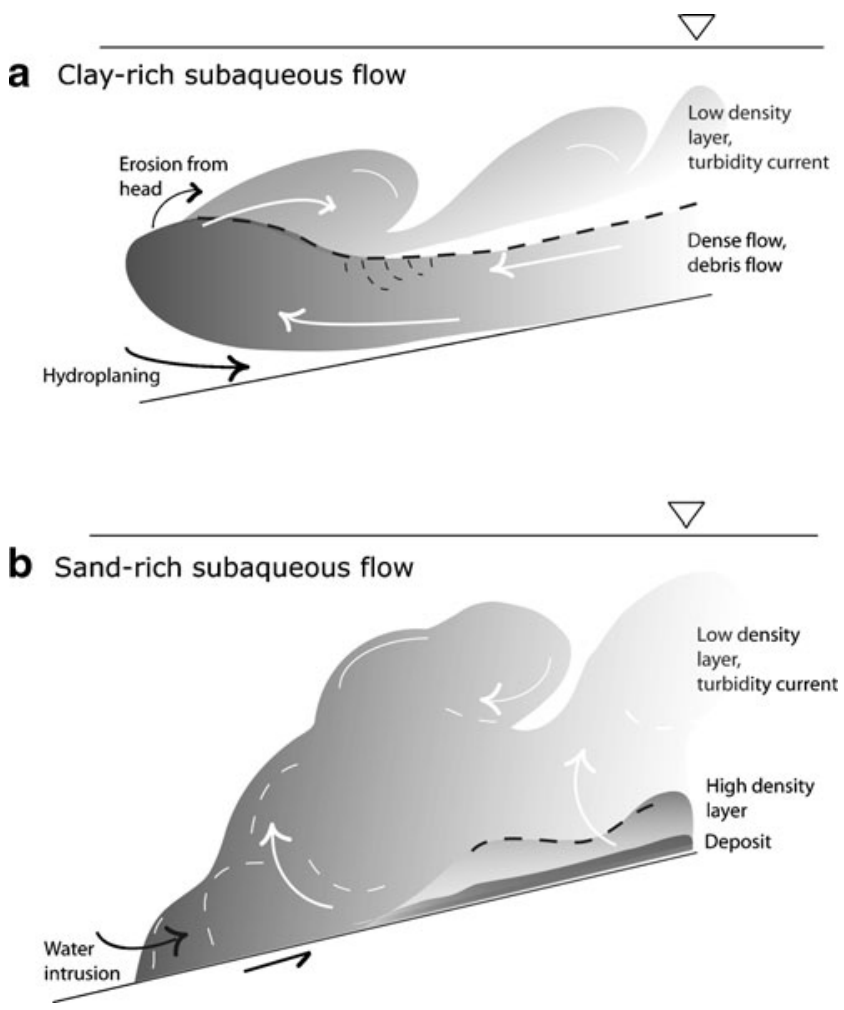

Fig. 10 Principal sketch of (a) subaqueous clay-rich debris flow and (b) subaqueous sandy debris as observed during the laboratory experiments

mechanism in this layer might be fluidisation in which the grains are carried by suspension but occasionally collide. The process of segregation is here slowed down by fluidisation. Hence, this support mechanism may have special implications for the run-out and transport of sand, as discussed by Breien et al. (in press). From Fig. 4a, we see that the total pressure is about twice the pore pressure, indicating that parts of the sand are being deposited and that hydroplaning does not take place after the passage of the front.

\section{Analysis}

\subsection{Flow regime and dynamics}

The visual observations as well as the velocity and pressure measurements in the laboratory provided information on flow regimes including the onset of hydroplaning. It became clear that subaqueous flows were highly transitional, with flow regime and support mechanisms changing as the debris flow slurry disintegrated and the composition changed. Although experimental studies provide valuable insight into the landslide dynamics, upscaling these results from laboratory to field scale represents a major challenge because of complex and conflicting similarity requirements. However, most clayey flows and many sandy flows that are still within the range of cohesive or transitional sediment mixtures can be scaled in terms of viscosity and yield strength for better predictions of huge landslides moving at high speed (see Appendix). Further information about the flow regimes can also be gained by estimating the Reynolds and Froude numbers even though significant uncertainties remain due to the break-up of the material and change of material properties during flow.

As an example, we consider the Reynolds number of the low-density layer of a subaqueous $5 \%$ clay flow. As previously discussed, we make the assumption that the debris flow can be transformed into a bipartite flow with a lower fluidised sandy layer and an upper sand-free low-density layer. Based on the thickness of the low-density layer observed close to the downstream cameras, we estimate a solid fraction (ratio of solid volume to total volume) decrease from the value $C=0.508$ in the original debris flow slurry to $C=0.018$ due to break-up. Using the Krieger-Dougherty formula for the viscosity, we find a viscosity $(\mu)$ of the order

$\mu \approx \mu_{0}\left(1-\frac{0.018}{C_{*}}\right)^{-2.5 C_{*}} \approx 1.05 \mu_{0}$

where $C_{*} \approx 0.6$ is the solid fraction corresponding to sand particle interlock, and $\mu_{0}$ is the viscosity of the pore fluid. We find that the viscosity of the debris flow slurry increases by a factor of 1.05 by adding sand. The Reynolds number

$\operatorname{Re}=\frac{U H \rho}{\mu}$

is consequently found to be of the order $\operatorname{Re} \approx 10^{5}$, which indicates turbulent conditions in the low-density layer as also seen from the videos (Breien et al. in press).

It is complicated to estimate the Reynolds number for the lower fluidised high-density sandy layer because sand grains partly interlock and the granular friction is certainly significant in the force balance. Due to segregation, breakup and water incorporation, the rheology changes as the mass flows through water. Densities were not measured during flow, and these calculations will therefore be based on estimates. The clay-rich subaqueous debris flows can be recognised as laminar from the video measurements (Breien et al. in press). As these flows are coherent non-Newtonian flows, where particle segregation and water incorporation are of minor importance, the Reynolds number can be calculated as

$\operatorname{Re} \approx \frac{U^{2-\alpha} H^{\alpha} \rho}{K}$

where $\alpha$ is the exponent in the Herschel-Bulkley model, and $K$ is the consistency parameter. The very low Reynolds numbers $(<100)$ we find by rheological measurements in the clay-rich flows $\left(K=20.8 \mathrm{~Pa} \mathrm{~s}^{\alpha}, \alpha=0.2\right)$ confirm a laminar regime. 
The square root of the ratio between the hydrodynamic stagnation pressure in front of the flow and the submerged weight per unit area of the flow defines the densimetric Froude number

$\mathrm{Fr}=\sqrt{\frac{\rho}{\Delta \rho g H \cos \beta}} U$

where $\rho$ is the water density, $\Delta \rho$ is the difference between the flow and the water densities, $g$ is the acceleration of gravity, $H$ is the flow depth and $\beta$ is the slope. When the stagnation pressure exceeds the submerged weight (i.e. Fr $\sim 1$ ), hydroplaning is present. Due to the hydrodynamic lift above the head, hydroplaning may occur already when $\mathrm{Fr}<1$. According to Mohrig et al. (1998), hydroplaning can start at Froude numbers as low as 0.4.

The densimetric Froude numbers for the more clayey experimental slurries vary from 1.5 to 1.65 . These values have been calculated assuming a density for the debris flow equal to the initial density of the debris flow slurry. For clay contents sufficiently high for the debris flows to remain coherent, such high Froude number values cause the debris flow to hydroplane. As mentioned above, partial hydroplaning of the debris flow slurry was observed with low clay contents as well.

\subsection{Longitudinal deformation and velocity field} development

As seen from the high-speed camera measurements and PIV analyses (Figs. 7, 8 and 9), the internal velocities are very dependent on the composition of the flow and also vary within the body. The differential velocities result in internal deformation of the flowing materials. The velocity is in general higher in the head than in the body. This difference is especially large in the high clay flows (Fig. 11). The higher velocity of the debris flow head compared to the body (which experiences higher bed friction) results in stretching and elongation of the flow. Through comparison of the velocities in two adjacent cameras $(50 \mathrm{~cm}$ apart), we get a measure of the amount of stretching throughout the body of the flow. At each camera position, the velocity field $(u(x, y, t), v(x, y, t))$ is resolved as

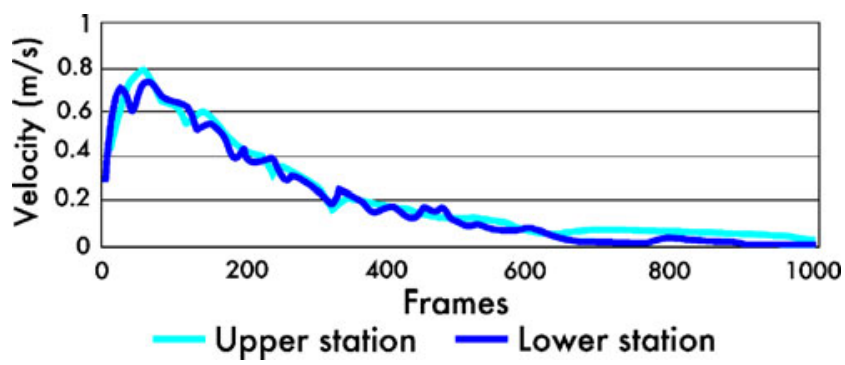

Fig. 11 Velocity development with time at upstream and downstream stations; $25 \%$ clay flow the debris flow slurry passes. A quantitative measure of the stretching rate of the mass is obtained by comparing the velocities at two adjacent camera stations (see Fig. 3):

$\varepsilon_{x x}=\frac{\partial v}{\partial x} \cong \frac{u_{1}-u_{2}}{\Delta x}$

where $u_{1}$ and $u_{2}$ are the velocities of the flow at two different camera positions, and $\Delta x$ is the distance between the cameras $(50 \mathrm{~cm})$. This gives the change in velocity over a given reference length. The stretching rate values are presented in Fig. 12. We found that stretching is highest in the clayey flows (up to $1.3 \mathrm{~s}^{-1}$ ), and the increase with increasing clay content seems exponential (Fig. 12), both at the upstream and downstream stations. We also find that the stretching of the body is largest in the frontal parts of the flow and decreases towards the tail. This is most pronounced in the clay-rich flows, showing the importance of the hydroplaning with reduced basal friction as an important mechanism for facilitating long run-out distances for clay-rich debris flows.

From the flume experiments, we found that one of the most important aspects in debris flow dynamics is the ability of the flow to preserve its original composition, and this ability is determined by the amount of fines in the debris flow slurry. Hydroplaning, stretching and a low degree of deposition are factors that enhance the run-out of clay-rich and coherent flows, and all are linked to the presence of clay. In some cases, the stretching can result in autoacephalation (Parker 2000), producing outrunner blocks and the development of multiple heads (Elverhoi et al. 2005; Ilstad et al. 2004c; Nissen et al. 1999; Prior et al. 1984; Hampton 1972). The elongation of the flowing body due to stretching decreases the thickness of the flow, and the fast-moving head 'pulls' the rest of the body. The phenomenon is most pronounced in clay-rich flows, which initially produce a small low-density layer, mainly from their heads, but after some distance, one could expect this stretching to result in an increase in potential mixing length due to development of cracks and incorporation of water.

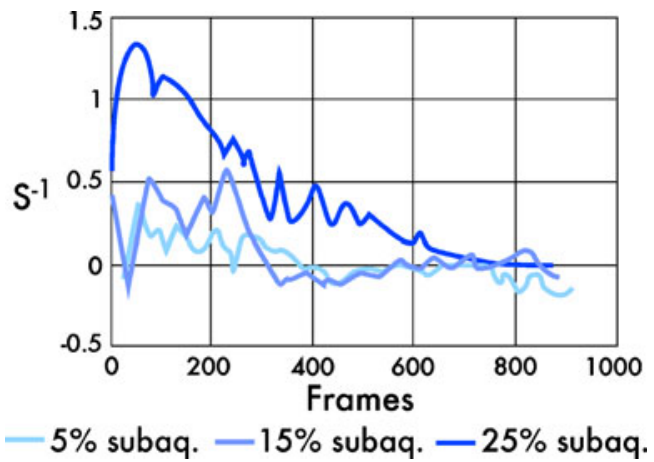

Fig. 12 Stretching rate of the debris flow mass, calculated from the velocities in two neighbouring cameras 
The mixing results in lower coherency and a depletion of fines and will hence ultimately lead to development of a sandier debris flow if the mass is allowed to travel far. In this way, extensive sandy deposits can form in deep marine environments, far from their source areas (Breien et al. in press). The low-density layer will continue, carrying mostly fines. This segregation of grain sizes is particularly visible in the subaqueous flows of lowest coherency ( $5 \%$ clay). This is due to low yield strength and continuous disintegration in such flows, and results in flow regimes, which a transitional both in the vertical and horizontal directions.

\subsection{Fragmentation and erosion}

Quantitative studies of the yield strength of slurries composed of clay, sand and water are scarce. However, in the laboratory, the rheological properties of the slurries were measured in a ball rheometer (Breien et al. in press; De Blasio et al. in press). The yield strength increases dramatically with the clay content, from about $5-10 \mathrm{~Pa}$ at $5 \%$ clay to $70-100$ at $25 \%$ clay (Fig. 4 , the intercept with the $y$-axis).

Talling et al. (2002) summarised results for the critical shear stress for surface erosion from various studies. For consolidated beds, this critical shear stress increases significantly with depth below the sediment surface and typically lies between 0.1 and $2 \mathrm{~Pa}$. Further, such critical shear stresses are one or two orders of magnitude lower than the yield strength measured by vane shear, falling cone or other rheometrical tests (Amos et al. 1997; Mitchener and Torfs 1996; Houwing 1999; Zreik et al. 1998). For sand-kaolinite suspensions with a clay fraction from $5 \%$ to $25 \%$, the critical shear stress for surface erosion measured by Mitchener and Torfs (1996) ranges between 0.5 and $5 \mathrm{~Pa}$. When the frictional stress on the flow/water interface exceeds the critical shear stress, surface erosion of the debris flow occurs.

The frictional stress is expressed by

$\tau \approx \frac{1}{2} c_{D} \rho U^{2}$

where $U$ is the velocity of the debris flow, $\rho$ is the water density and $c_{D}$ is the frictional drag coefficient on the flow/ water interface. Following Norem et al. (1990), the frictional drag coefficient $c_{D}$ averaged over the flow length $L$ is defined through the equation proposed by Schlichting (1980) for turbulent flow along a flat rough plate moving with slowly varying velocity:

$c_{D}=[1.89+1.62 \log (L / k)]^{-5 / 2}$

where $k$ is a roughness length in the range $0.01-0.1 \mathrm{~m}$. Hence, based on this approach, $c_{D}$ will be around 0.016 . Young (1989) reported frictional drag coefficients up to about 0.02 for turbulent flows above rough flat plates. The frictional stress may be higher around the blunt head than above the flatter and longer main body of the flow. However, for a low-density layer constituting a significant part of the total flowing mass (as observed for the Grand Banks and the Storegga first phase landslides) to be formed, it is assumed that particles must be brought into suspension not only from the flow head. Hence, the analysis of critical shear stresses refers to the main body of the flow.

Applying the coefficient values discussed above, the frictional stress associated with a velocity of $U \approx 1 \mathrm{~m} / \mathrm{s}$ (observed in the laboratory experiments and slightly dependent on the composition; Breien 2009) is between 5 to $10 \mathrm{~Pa}$. Figure 13 shows with asterisks the frictional stress as a function of the clay content. The frictional stress increases slightly as a function of the clay content because of the increase in the velocity of the slurry. In the same plane, the critical shear stresses for surface erosion, assumed equal to $10 \%$ of the yield strength, are shown with circles. Their dependence on the clay content is much more dramatic because, as we have discussed, the clay determines a significant increase of the cohesion. The two lines cross at a critical clay density, which from the experimental evidence falls between $20 \%$ and $25 \%$ clay content. A main conclusion from the laboratory experiments is thus that a bipartite flow is expected to occur when the critical shear stress is smaller than the frictional stress (clay-to-sand ratio $<20-25 \%$ ), while a coherent debris flow occurs when the critical shear stress is larger than the frictional stress (clay-to-sand ratio $>20-25 \%$ ). This is confirmed by the flume experiments. Significant uncertainties, highlighted by the shaded areas in Fig. 13,

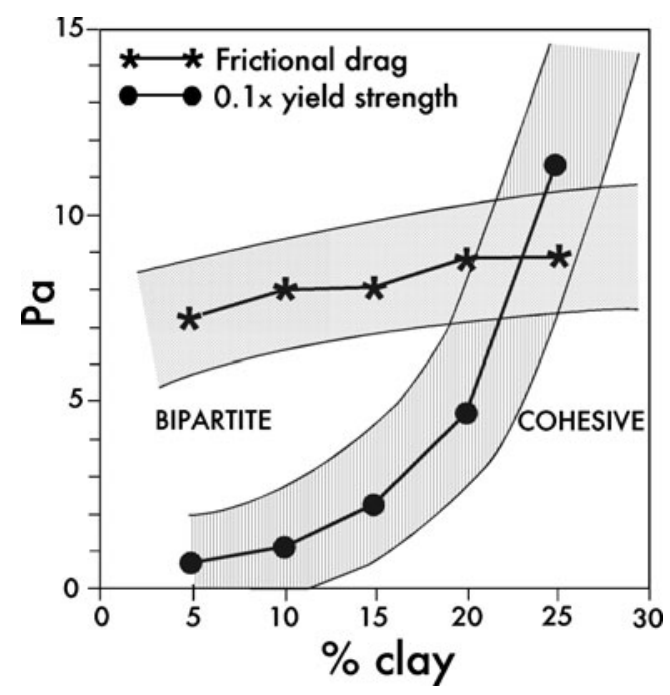

Fig. 13 Comparison between the frictional stress on the flow/water interface and the critical shear stress for erosion as a function of clay content. The figure illustrates that the range of flows containing 0 $20 \%$ clay evolves into bipartite flows whilst flows containing more than $20 \%$ clay stay cohesive 
prevent a quantitative first-principle determination of the line of crossing, which is found in retrospect based on the results of the experiments.

\section{Modelling the landslide velocities}

\subsection{Sediment sources}

The Storegga landslide, the Bear Island Fan complex and the Grand Banks landslide are all associated with glacially influenced margins. All three landslides originated from sediments provided from major ice sheets: (1) the Storegga landslide from the Fennoscandian ice sheet, (2) the Bear Island Fan landslides from the Barents Sea ice sheet and (3) the Grand Banks landslide from the Laurentian ice sheet. In principle, the sediment sources are similar, namely, glacially eroded products, a situation likely to provide rather equal conditions and products. However, as documented from the three locations, the final deposits in the three sites differ strongly. In particular, extensive sand deposits on the abyssal plain similar to those associated with the Grand Banks landslide have not been found in connection with the other two landslides. As seen from the experiments, the primary composition plays an important role in the subsequent behaviour. Initial high clay content- or cohesive sediments - provides landslides that may remain as massive debris flows without disintegration. When comparing the source area of the three landslides, they differ in significant aspects. The source material of the Bear Island Fan complex largely originates from the Barents Sea, an area entirely dominated by sedimentary rocks including large amounts of shale and fine-grained rocks. Sedimentological and mineralogical analyses of the source sediments demonstrate high contents of clay minerals such as illite, chlorite, kaolinite, smectite and random mixed-layer smectite-illite (Elverhoi et al. 1989; Knies et al. 2006). A similar assemblage although with a somewhat greater smectite content has been identified in the surface as well as in deeper sections along the margin (Knies et al. 2006; Forsberg et al. 1999). With respect to the source material, the Storegga landslide materials have a mixed source from the Fennoscandian shield underlain by crystalline and metamorphic rocks with additional supply from the Norwegian shelf, underlain by sedimentary rocks characterised by a high clay content. It should also be noticed that mineralogical analyses of Storegga landslide materials reveal significant amounts of smectite (Forsberg and Locat 2005). Thus, similar to the Bear Island Fan sediments, the Storegga landslide sediments have a cohesive nature. The Grand Banks landslide sediments consist of a mixture of mud as well as sand and gravel (Piper and Slatt 1977; Stow 1981; Piper et al. 1984). Clay mineral assemblages show a dominance of illite and chlorite with additional kaolinite as well as some amounts of smectite. Although the clay mineral assemblages may have some common characteristics in all three areas, it seems likely that the Storegga and the Bear Island Fan landslides may have a somewhat higher content of active clay minerals such as smectite. A more significant difference is most likely the sand and gravel contents in the Grand Banks landslide. Such sediments have not been found in association with the two other landslides. Thus, a significant difference in gross sediment properties may exist between the various regions, cohesive sediments along the Norwegian margin while the Grand Banks landslide may originate from a more mixed sediment source characterised by less active clay minerals as well as a higher content of granular components, resulting in a potentially less cohesive landslide.

\subsection{Landslide velocity calculations}

In this paper, we deal with two models for back calculating the landslides. The first model BING (Imran et al. 2001) is a depth-integrated two-dimensional model of a debris flow described by a Bingham or a Herschel-Bulkley rheology. The model is detailed in Imran et al. (2001). The basic tenet of the model is that a debris flow continues travelling until the shear stress is lower than the yield strength of the material. The debris flow geometry is divided into a series of elements shaped as parallelepipeds. Neglecting here for the sake of reasoning the interaction of each element with its neighbours and the fact that the elements change shape, the acceleration of one element is approximately given as

$$
\begin{aligned}
\left(1+A \frac{\rho_{W}}{\rho}\right) \frac{d U}{d t} \approx & g \sin \beta-\frac{\tau_{y}}{\rho D}-\frac{\mu U}{\rho D^{2}}-\frac{1}{2} \frac{\rho_{W}}{\rho} \\
& \times\left[\frac{c_{P}}{L}+\frac{c_{D}}{D}\right] U^{2}
\end{aligned}
$$

where $c_{P}$ and $c_{D}$ are the pressure and frictional drag coefficients, $\tau_{y}$ is the yield strength, $\mu$ is the Bingham viscosity, $L$ is the length of one debris flow parallelepiped, $\beta$ is the slope angle, $\rho_{w}$ is the water density, $\mathrm{A}$ is a parameter accounting for the added mass and $D$ is the flow depth of the debris flow parallelepiped. The terms on the right hand side are derived from the gravity component along the slope, the basal yield stress, the basal viscous stress and the pressure and upper surface frictional stress on the flow. The velocity and run-out distance depend in a critical manner on the rheological properties of the model.

A second model used in this work is W-BING (water BING; De Blasio et al. 2004). Simulations with W-BING are affected by more uncertainties compared to BING, not only because the process of hydroplaning is not fully understood but also because the presence of a water layer is a more difficult condition to achieve computationally. The model starts as the normal BING model, and hydroplaning is incorporated when the densimetric Froude number Fr is $>0.4$ 
as described above (De Blasio et al. 2004). The change in water layer thickness is calculated from the Navier-Stokes equations. The shear resistance between the debris flow and the base is significantly reduced where the water layer is present because most of the deformation is carried by the low-viscous water layer. An approximate equation of motion for the hydroplaning debris flow becomes

$$
\begin{aligned}
\left(1+\alpha \frac{\rho_{W}}{\rho}\right) \frac{d U}{d t} \approx & g \sin \beta-\frac{\mu_{W} U}{D_{W} D \rho}-\frac{1}{2} \frac{\rho_{F}}{\rho} \\
& \times\left[\frac{c_{P}}{L}+\frac{c_{D}}{D}\right] U^{2}
\end{aligned}
$$

where $\mu_{w}$ and $D_{w}$ are the viscosity and the thickness of the water layer, respectively. The new term $-\frac{\mu_{W} U}{D_{W} D \rho}$ replaces the basal yield and viscous stresses and is usually much lower in magnitude. This is in essence the lubricating effect of hydroplaning. Hence, a longer simulated run-out distance is normally achieved in the presence of hydroplaning.

\subsection{Results of model simulations}

Figures 14 and 15 show the results for the Bear Island Fan complex and the Grand Banks landslide, respectively. For the Bear Island Fan simulation, we changed the rheological properties of the debris flow until values compatible with the observed run-out were achieved. Because our tenet is that the Bear Island Fan debris flows were hydroplaning and that high yield strength was preserved, we seek a

Bear Island $30 \mathrm{kPa}$
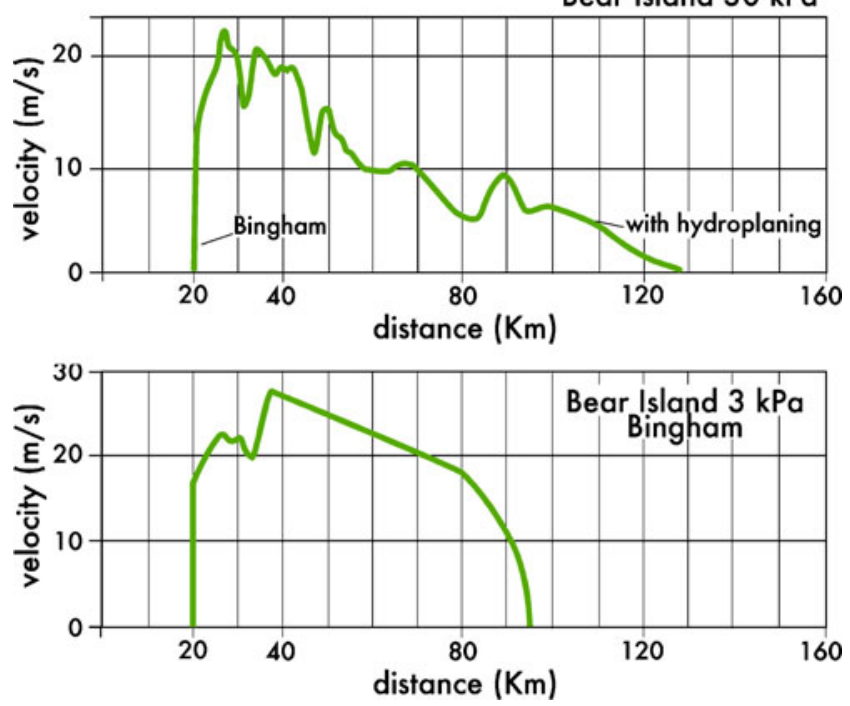

Fig. 14 Simulation, debris flow: Bear Island Fan complex. Upper figure: simulation with $\mathrm{W}-\mathrm{BING}$ and $30 \mathrm{kPa}$. The calculation with BING and the same yield stress results in only an extremely short runout. Lower figure: in order to gain a longer run-out with BING, a yield stress as low as $3 \mathrm{kPa}$ is necessary. (Notice: the slope along the Grand Banks is much longer than that of the Bear Island Fan complex. This causes a shorter run-out of the Bear Island simulation with the BING model.)
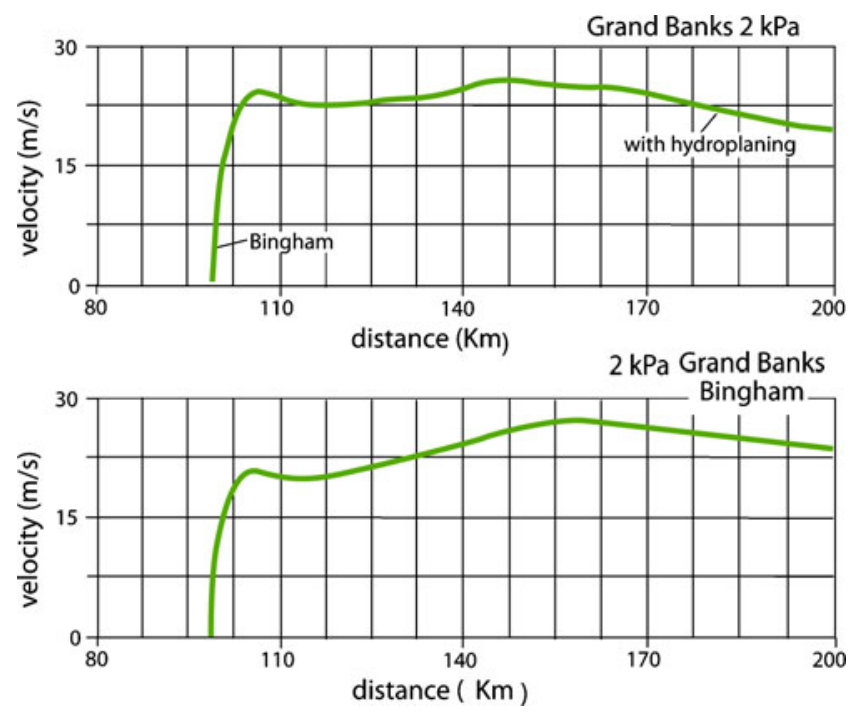

Fig. 15 Simulation debris flow part of Grand Banks landslide with a yield stress of $2 \mathrm{kPa}$. Upper figure: with W-BING. Lower figure: with BING. Notice that the slope along the Grand Banks is much longer than that of the Bear Island fan. This causes a shorter run-out of the Bear Island simulation with the BING model

solution of our modelling using W-BING. The figure shows that the model reasonably reproduces the observed run-out with a yield strength of $30 \mathrm{kPa}$. The maximum calculated velocity is above $22 \mathrm{~m} / \mathrm{s}$. A similar calculation with a nonhydroplaning 30-kPa debris flow (BING model) merely results in a small readjustment of the material. To gain a run-out compatible with the observations in the absence of hydroplaning, much lower yield strengths should be adopted: between 1.5 and $3 \mathrm{kPa}$ (Fig. 14 shows the result with $3 \mathrm{kPa}$ ). This range of low values entails a thorough transformation of the rheology, which is not compatible with the sharp edges and the thickness of the Bear Island Fan lobes. We conclude that the Bear Island Fan debris flow did not disintegrate (as also indicated by the clay-rich cohesive nature of the Bear Island Fan clay), and that its dynamics are well reproduced by our experiments with high clay content (Fig. 16a). It should also be noticed that the observed lack of basal erosion between the various debris flows at the Bear Island Fan complex (Laberg and Vorren 2000) may be related to that hydroplaning significantly reduces erosion of the antecedent sediments (e.g. Mohrig et al. 1999; Harbitz et al. 2003; Elverhoi et al. 2005).

Figure 15 shows the results for the Grand Banks landslide. Following our principle, the mechanics of this debris flow were different from the Bear Island Fan debris flows. Based on the analogy with experiments with intermediate and low clay content, we suggest that the Grand Banks landslide did disintegrate, transforming from a less cohesive debris flow into a bipartite flow, and finally continuing as a pure turbidity current (Fig. 16b). It is difficult at the present stage to fix the distance from start at which the cohesive Grand 
Fig. 16 a Principal diagram illustrating the flow behaviour of one tentative debris flow at the Bear Island Fan complex and the Storegga landslide phase 1. Bear Island Fan complex is characterised by cohesive/ coherent debris flows leading to hydroplaning and longitudinal extension ('stretching'). b Principal diagram illustrating the flow behaviour of the 1929 Grand Banks landslide (background data and topographic profile adopted from Heezen et al. 1954). Initial phase with debris flows, high-speed acceleration due to hydroplaning followed by transformation into a bipartite flow; i.e. high-density sand-rich unit (fluidised laminar flow) and a low-density turbidity current. Continuous deposition of sand from fluidised unit, accordingly no erosion at the base of the fluidised unit

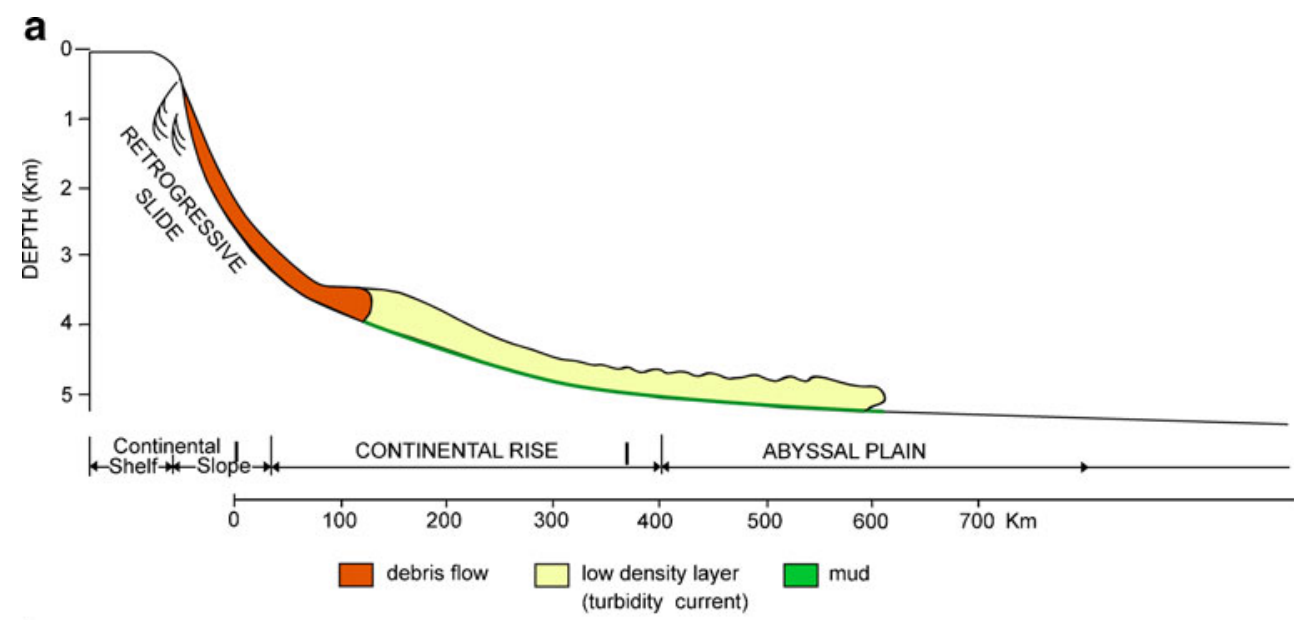

b

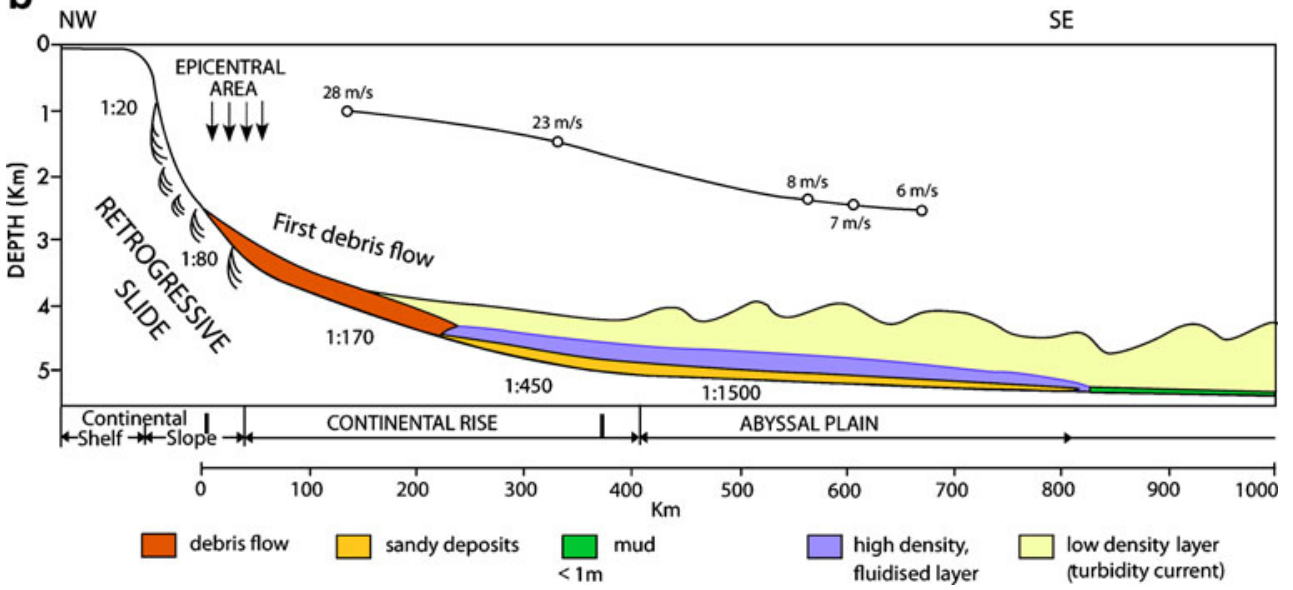

Banks landslide transformed into a bipartite flow. Another thorny task is to establish both the origin of the specific part of the entire landslide that broke the cables and the provenance of the sandy material that was deposited both in the middle and in the far basin. The cable break was recorded after slightly less than $1 \mathrm{~h}$ from the main shock, which sensibly limits the distance between the head of the initial debris flow at its site of initiation and the first cable to be no more than $100 \mathrm{~km}$. We assume that the head of the initial 1929 Grand Banks landslide may have been located in the area of the quake epicentre, at a distance of $100 \mathrm{~km}$ from the first cable break (see Fig. 16b). In response to the retrogressive failure, debris flows were subsequently mobilised at gradually shallower water depths, successively forming new pulses of bipartite flows that continued out onto the abyssal plain and gradually established the observed sand layer with a thickness of up to $1 \mathrm{~m}$. Such failures could not be recorded by the cables that had already been broken by the primary slide.

We suggest that the transformation cohesive-to-bipartite flow occurred after the front of the debris flow had passed a distance of 50 to $100 \mathrm{~km}$ beyond the first cable. The modelling results in Fig. 15 illustrate some crucial aspects of the flow dynamics in the initial phase of the landslide development. Under the assumption of a mass failure followed by an initial debris flow regime - as indicated by the field dataacceleration of the masses was crucial. As seen from the simulation (W-BING), a situation with hydroplaning provides high velocities, potentially corresponding to the observations of cable break as well as velocities of almost $30 \mathrm{~m} / \mathrm{s}$ as required to generate the 1929 Grand Banks tsunami (Fine et al. 2005). High velocities are required also to generate the low-density layer causing distal turbidites (Fig. 16a, b).

High velocities of the 1929 Grand Banks landslide may also be obtained through a more classical visco-plastic flow as illustrated by the BING simulation. A lower shear strength of the initial material is, however, required in order to reach long run-out distances and high velocities. Although the results for BING and W-BING for the first $200 \mathrm{~km}$ of simulations are not fundamentally different, the simulations show that if the landslide consists of materials with a low shear strength, high velocities and long run-out distances may be obtained even without hydroplaning. However, in cases with sufficient cohesiveness and velocity of the sliding materials, a subaqueous landslide may evolve into a hydroplaning regime (e.g. Mohrig et al. 1998). Thus, based on the observations of 
debris flows in the Grand Bank landslide area originating from at least partly muddy sediments (e.g. Piper et al. 1999), a certain degree of cohesiveness seems likely. Accordingly, a hydroplaning scenario may also be likely for the 1929 Grand Banks landslide. It is also interesting to notice the observation of areas with little or no sign of erosion in the Grand Banks landslide area (e.g. Piper et al. 1999). As discussed for the Bear Island Fan complex, this may be related to hydroplaning masses.

In analogy with the medium and low clay content experiments, it is suggested that after the Grand Banks landslide started to break up, it continuously lost mass in the form of a sand carpet depositing along the abyssal plain as described by Breien et al. (in press). Whereas the sand in the distal part was the product of the first phase of high-density fluidised layer of the Grand Banks landslide, the 1-m thick deposits appearing only at distances less than $400 \mathrm{~km}$ from the headwall might be at least partially the result of the successive events in response to the development of a retrogressive landslide.

Simulations of the Storegga first phase landslides reveal a difficulty in delivering a huge mass of sediment to the deep basin $400-500 \mathrm{~km}$ from the headwall applying a pure Bingham fluid concept (De Blasio et al. 2005). In order to obtain the observed long travel distance and velocities of $25-30 \mathrm{~m} / \mathrm{s}$ required to generate the Storegga landslide tsunami with a retrogressive landslide motion (Harbitz et al. 1993; Bondevik et al. 2005), the first phase landslide is simulated with hydroplaning and/or a material progressively remoulding from $20 \mathrm{kPa}$ to $500 \mathrm{~Pa}$ during flow. The high velocities are also required in order to form the low-density layer causing the distal turbidites (Fig. 2). The shorter travel distance of the highly consolidated material in the smaller landslides of the Storegga termination phase (Fig. 2) is successfully simulated as a (one-layer) shear softening debris flow (Gauer et al. 2005).

Finally, note that a key requisite for hydroplaning is that the initial velocity of the non-hydroplaning flows has to be relatively high to ignite the process. An initial high velocity is a consequence of the initially thick geometry of the debris flow. In a Bingham rheological model (with a more general model of Herschel-Bulkley fluid, the argument is only slightly different), the initial acceleration increases with the debris flow thickness $D$. This is clearly noticeable from Eq. 8, where the second and third terms on the right hand side decrease in magnitude as a function of $D$. As a consequence, high acceleration may be attained in the beginning of the failure only if the sediment is sufficiently thick. However, as the debris flow stretches and becomes thinner, the internal resistance becomes comparatively more important than gravity. Thus, unless hydroplaning starts, the debris flow will stop at an early stage, unless the yield stress and the viscosity are very small.
7.4 Relationship with the experimental cohesive-bipartite transition

It has been shown (Fig. 13) that cohesive versus disintegrating bipartite dynamics in experimental debris flows can be explained based on a comparison between the frictional stress on the flow/water interface that remains nearly constant and the critical shear stress for erosion that strongly depends on the composition. We suggest that a similar principle could occur for natural submarine debris flows. Because the Grand Banks landslide potentially had a more granular and less cohesive composition, we expect a lower critical shear stress for erosion compared to the Bear Island Fan complex (Fig. 13). In our interpretation, the Bear Island Fan complex corresponds to the clay-rich experiments, while the Grand Banks landslide is featured by more sand-rich experiments. It should be noted that according to our simulations, the simulated velocities in the Bear Island Fan and the Grand Banks differed relatively more than the velocities of the clayrich and sand-rich debris flows seen in the experiments. However, the higher simulated velocities at the Grand Banks can be ascribed to a greater slope angle. Considering the uncertainties involved, the results seem to be compatible with our conjecture. Based on velocity estimates, the frictional stress in the field may be 500-1,500 times greater than in the experiments, which correspond to maximum values of the order $5-15 \mathrm{kPa}$. Therefore, the $30 \mathrm{kPa}$ adopted in the simulation of the Bear Island Fan would explain the absence of erosion and the maintenance of a cohesive state. In contrast, the critical stress for erosion is lower for the Grand Banks landslide.

\section{Conclusions}

The apparent differences in flow dynamics for the Bear Island Fan complex, the Storegga landslide and the 1929 Grand Banks landslide are elucidated by laboratory experiments with subaqueous debris flows of varying sand-to-clay ratio. The experiments reveal how the primary composition of the mobilised sediment (clayey versus sandy) determines the flow behaviour of submarine landslides.

We conclude that clay-rich cohesive material, as found e.g. at the Bear Island Fan complex and in the Storegga landslide, may remain compact and attain extremely long run-out distances and high velocities on very gentle slopes in the ocean as a result of hydroplaning and acceleration of the head of the flow causing longitudinal extension of the entire body.

If the sand content is increased, as e.g. in the Grand Banks landslide, the flow becomes less cohesive. This leads to internal particle segregation and a bipartite flow with the finer clay and silt forming an upper low-density layer, while the coarser material forms a lower sandy granular high- 
density layer. The process of particle segregation is a response to water intrusion and fluidisation and implies that the flow sprinkles sand on the seabed as it moves along, continuously loosing mass on its way and leaving behind a carpet of sand. This process also significantly reduces the erosive capability of the flow. Hydroplaning is still considered important to accelerate the frontal part of the debris flow to the velocities required for entrainment of particles from the head and frontal part of the debris flow, thus bringing particles into suspension and forming the upper low-density layer.

Acknowledgments The authors wish to thank Prof. Bjørn Gjevik for all his lectures and supervision in fluid mechanics, which havetogether with his open mind and broad field of interests - constituted an essential part of the basis for our studies of submarine landslide dynamics. The authors are further indebted to Dieter Issler, Peter Gauer, Johan Petter Nystuen and Kaare Høeg, as well as Jeff Marr, Gary Parker and their colleagues at St. Anthony Falls Laboratory, University of Minnesota, for their contributions to our studies of submarine landslides.

The work on the present paper has been supported by the International Centre for Geohazards (ICG) and the VISTA programme (a co-operation between the Norwegian Academy of Sciences and Statoil, project 6249). Additional support has also been provided by the Norwegian Geotechnical Institute, Department of Geosciences at the University of Oslo and the Research Council of Norway (NFR). This is contribution no. 304 of the International Centre for Geohazards.

Open Access This article is distributed under the terms of the Creative Commons Attribution Noncommercial License which permits any noncommercial use, distribution, and reproduction in any medium, provided the original author(s) and source are credited.

\section{Appendix}

Distorted scaling of subaqueous debris flows

Idealised laboratory-scale experiments may not relate directly to the full-scale natural phenomenon. Hence, scaling aspects must be considered when performing such experiments. In many cases of interest, the flow dimensions can be scaled down in the model, while the dimensions of the microstructure (e.g. grain size) cannot. For instance, a sandy debris flow cannot be scaled down using clay instead of sand because the properties of cohesive material differ greatly from that of non-cohesive sand. In such cases, the link between field and laboratory is made through distorted geometric modelling in which the vertical and horizontal dimensions are scaled down by different amounts, as done by Graf (1971), Marr et al. (2001) and Mohrig and Marr (2003). Focussing on the rheological properties of the sediment (i.e. viscosity and yield strength), rather than grain size and interactions, circumvents the problem of scaling the microstructure. The following procedure will apply to a Herschel-Bulkley fluid with exponent $\alpha$ under laminar flow conditions so that the vertical velocities are low except in the ambient fluid around the head.

To see the scaling relationships that are generated by distorted geometric modelling (following Marr et al. 2001), let $\lambda_{v}$ and $\lambda_{h}$ represent the vertical and horizontal scaling reductions, respectively. Thus where $H, B, A$ and $S$ denote debris flow thickness, width, cross-sectional area and slope, the dimensions of the laboratory model relative to the prototype are

$(H)_{l}=\lambda_{v}(H)_{p}$

$(B)_{l}=\lambda_{h}(B)_{p}$

$(A)_{l}=\lambda_{h} \lambda_{v}(A)_{p}$

$(S)_{l}=\frac{\lambda_{v}}{\lambda_{h}}(S)_{p}$

Dynamic similarity is obtained by ensuring equality of the appropriate dimensionless numbers. Let $U, \rho_{w}, \rho_{d}, g, \tau_{d y}$ and $\nu_{d}$ represent flow velocity, water density, debris flow density, acceleration of gravity, debris flow yield strength and kinematic Herschel-Bulkley viscosity, respectively. For subaqueous debris flows, we seek equality in the densimetric Froude number Fr, the Reynolds number $\operatorname{Re}$ and a dimensionless yield strength parameter Ys, defined by

$\mathrm{Fr}=\frac{U}{\sqrt{\left(\frac{\rho_{d}}{\rho_{w}}-1\right) g H}}$

$\operatorname{Re}=\frac{U^{2-\alpha} H^{\alpha}}{v_{d}}$

$\mathrm{Ys}=\frac{\tau_{d y}}{\rho_{d} U^{2}}$

In performing similarity analysis, we assume that $g, \rho_{w}$ and $\rho_{d}$ are the same in the model and the prototype. Since flow thickness $H$ is a vertical scale, the application of Froude similarity yields the result:

$(U)_{l}=\lambda_{v}{ }^{\frac{1}{2}}(U)_{p}$

The additional application of Reynolds similarity requires that

$\left(v_{d}\right)_{l}=\lambda_{v}{ }^{1+\alpha / 2}\left(v_{d}\right)_{p}$

Similarity in Ys gives

$\left(\tau_{d y}\right)_{l}=\lambda_{v}\left(\tau_{d y}\right)_{p}$

Table 1 provides an example of how the proposed experiments might be extrapolated to field scale assuming 
Table 1 Example values for extrapolation from laboratory experiments to field scale for a Bingham fluid

\begin{tabular}{llcr}
\hline Parameter & Symbol & $\begin{array}{l}\text { Laboratory } \\
\text { model }\end{array}$ & Prototype \\
\hline Slope angle & $\theta=\tan ^{-1} S$ (degrees) & 5 & 1 \\
Thickness & $H(\mathrm{~m})$ & 0.05 & 5 \\
Runout & $L_{r}(\mathrm{~m})$ & 20 & 10,000 \\
Width & $B(\mathrm{~m})$ & 0.2 & 100 \\
Discharge & $Q_{d}\left(\mathrm{~m}^{3} / \mathrm{s}\right)$ & 0.01 & 5,000 \\
Velocity & $U(\mathrm{~m} / \mathrm{s})$ & 1 & 10 \\
Viscosity & $\nu_{d}\left(\mathrm{~m}^{2} / \mathrm{s}\right)$ & 0.001 & 1 \\
Yield strength & $\tau_{d y}(\mathrm{~Pa})$ & 20 & 2,000 \\
\hline
\end{tabular}

$\lambda_{v}=1 / 100, \lambda_{h}=1 / 500$ and a Bingham fluid $(n=1)$. In the table, $L_{\mathrm{r}}$ is runout length (a horizontal quantity), and $Q_{d}$ is the volume discharge (cubic metres per second) of the debris flow. The values for the model are taken from typical results by Mohrig et al. (1998).

The values computed above are realistic for both model and field scale (even though the runout length of the laboratory experiments is unknown, most flows were still moving when they reached the end of the flume). This example shows that by scaling down the rheological parameters of the sediment and scaling up the slope angle, it is possible to model fieldscale debris flows in the laboratory — at least with regard to the bulk properties of the flow.

In practical terms, viscosity and yield strength may be reduced in the synthetic sediment by adding water to the slurry and reducing the clay content or using a different type of clay. As Eqs. 19 and 20 show, the slurry viscosity needs to be reduced. Both water and clay content will therefore usually need to be changed in going from field to laboratory scale. Care has to be taken that this does not significantly change the exponent $\alpha$. We may conclude that, in general, flow regime transitions will not occur at the same clay content values at all scales. Moreover, different types of clay may induce different flow behaviour even with the same clay content, and this clay-type dependency may also be scale-dependent.

Finally, some types of sediment are not well described by visco-plastic models (i.e. through viscosity and yield strength) and therefore need to be scaled following different considerations (Iverson 1997). These include coarse slurries or sandy debris flows in which frictional and inertial effects dominate. The grain size, $d$, is significant for shear stresses in these kinds of granular flows and for settling velocities in suspension flows.

For example, in the turbidity current forming above the debris flow, the settling velocity should scale in the same way as the horizontal velocity and the square root of the turbulent energy density, i.e. with $\lambda_{v}{ }^{1 / 2}$ to reproduce the settling behaviour. This leads to the requirement

$(d)_{p}=\lambda_{v} \frac{c_{D}\left(\operatorname{Re}_{p}\right)}{c_{D}\left(\operatorname{Re}_{l}\right)}(d)_{l}$

In the ambient fluid, the viscosity will normally be the same in nature and in the laboratory, thus the Reynolds numbers in the ambient fluid around the debris flow body will differ by several orders of magnitude. This can be tolerated as long as the Reynolds number at the laboratory scale is well above the transition to fully turbulent flow. In Eq. 21, however, the particle Reynolds numbers determined by the settling velocity and the particle diameter have to be applied, and a suitable particle diameter must be determined by solving the nonlinear Eq. 21 for $(d)_{l}$. In our case, the clay particles in the laboratory roughly correspond to sand particles in a full-size debris flow. This indicates that the turbidity current generated by the field-scale debris flow would be competent enough to suspend sand and transport it over considerable distances.

Despite all these complications, however, most clayey flows and many 'sandy' flows that are still within the range of cohesive (more fines) or transitional (less fines, more sand) sediment mixtures, can be scaled in terms of viscosity and yield strength.

\section{References}

Amos CL, Feeney T, Sutherland TF, Luternauer JL (1997) The stability of sublittoral fine grained sediments in a subarctic estuary. Sedimentology 43:1-19

Baas JH, Best JL, Peakall J, Wang M (2009) A phase diagram for turbulent, transitional, and laminar clay suspension flows. J Sed Res 79:162-183

Barbolini M, Biancardi A, Natale L, Pagliardi M (2005) A low cost system for the estimation of concentration and velocity profiles in rapid dry granular flows. Cold Reg Sci Technol 43:49-61

Bondevik S, Løholt F, Harbitz CB, Mangerud J, Dawson A, Svendsen JI (2005) The Storegga Slide tsunami-comparing field observations with numerical simulations. Mar Petrol Geol 22:195-208

Breien H (2009) On the dynamics of subaqueous and subaerial gravity mass flows - a comparison. Ph.D. Thesis, Faculty of Mathematics and Natural Sciences, University of Oslo, Oslo

Breien H, Pagliardi M, Elverhoi A, De Blasio FV, Issler D (2007) Experimental studies of subaqueous vs. subaerial debris flowsvelocity characteristics as a function of the ambient fluid. In: Lykousis V, Sakellariou D, Locat J (eds) Submarine mass movements and their consequences. Dordrecht, Springer, pp 101-110

Breien H, De Blasio FV, Elverhoi A, Nystuen JP, Harbitz CB (in press) Transport mechanisms of sand in deep-marine environmentsinsights based on laboratory experiments. J Sediment Res

Bryn P, Berg K, Forsberg CF, Solheim A, Kvalstad TJ (2005) Explaining the Storegga Slide. Mar Petrol Geol 22:11-19

Coussot P, Piau JM (1994) On the behaviour of fine mud suspensions. Rheologica Acta 33:175-184

De Blasio FV, Engvik L, Harbitz CB, Elverhoi A (2004) Hydroplaning and submarine debris flows. J Geophys Res 109:C01002. doi:10.1029/2002JC001714 
De Blasio FV, Elverhoi A, Issler D, Harbitz CB, Bryn P, Lien R (2005) On the dynamics of subaqueous clay rich gravity mass flows - the giant Storegga slide, Norway. Mar Petrol Geol 22:179-186

De Blasio FV, Elverhoi A, Engvik L, Issler D, Gauer P, Harbitz C (2006) Understanding the high mobility of subaqueous debris flows. Norw J Geol 86:275-284

De Blasio FV, Breien H, Elverhoi A (in press) Modelling a cohesivefrictional debris flow: an experimental, theoretical and fieldbased study. Earth Surf Process Land

Dimakis P, Elverhoi A, Høeg K, Solheim A, Harbitz C, Laberg JS, Vorren TO, Marr J (2000) Submarine slope stability on the highlatitude glaciated Svalbard-Barents Sea margin. Mar Geol 162:303-316

Elverhoi A, Pfirman S, Solheim A, Larsen BB (1989) Glaciomarine sedimentation and processes on high Arctic epicontinental seasexemplified by the northern Barents Sea. Mar Geol 85:225-250

Elverhoi A, De Blasio FV, Butt FA, Issler D, Harbitz C, Engvik L, Solheim A, Marr J (2002) Submarine mass-wasting on glaciallyinfluenced continental slopes: processes and dynamics. In: Dowdeswell JA, Cofaigh CO (eds) Glacier-influenced sedimentation on high-latitude continental margins, vol 203. Geological Society of London, London, pp 73-87

Elverhoi A, Issler D, De Blasio FV, Ilstad T, Harbitz CB, Gauer P (2005) Emerging insights into the dynamics of submarine debris flows. Nat Haz Earth Sys Sci 5:633-648

Fine IV, Rabinovich AB, Bornhold BD, Thomsen RE, Kulikov EA (2005) The Grand Banks landslide-generated tsunami of November 18, 1929: preliminary analysis and numerical modeling. Mar Geol 215:45-57

Forsberg CF, Locat J (2005) Mineralogical and microstructural development of the sediments on the Mid-Norwegian margin. Mar Petrol Geol 22:109-122

Forsberg CF, Solheim A, Elverhoi A, Jansen E, Channell JET, Andersen ES (1999) The depositional environment of the western Svalbard margin during the late Pliocene and the Pleistocene: sedimentary facies changes at site 986 . In: Raymo ME, Jansen E, Blum P, Herbert TD (eds) Proceedings of the Ocean Drilling Program, scientific results, vol 162. Ocean Drilling Program, College Station, Texas, pp 233-246

Gauer P, Kvalstad TJ, Forsberg CF, Bryn P, Berg K (2005) The last phase of the Storegga Slide: simulation of retrogressive slide dynamics and comparison with slide-scar morphology. Mar Pet Geol 22:171-178

Gauer P, Elverhoi A, Issler D, De Blasio FV (2006) On numerical simulations of subaqueous slides: back-calculations of laboratory experiments of clay-rich slides. Norw J Geol 86:295-300

Graf WH (1971) Hydraulics of sediment transport. McGraw Hill, New York, $513 \mathrm{pp}$

Haflidason H, Lien R, Sejrup HP, Forsberg CF, Bryn P (2005) The dating and morphometry of the Storegga Slide. Mar Petrol Geol 22:123-136

Hampton MA (1972) The role of subaqueous debris flows in generating turbidity currents. J Sed Petrol 42:775-793

Harbitz CB, Pedersen G, Gjevik B (1993) Numerical simulation of large water waves due to landslides. J Hydraul Eng 19:1325-1342

Harbitz CB, Parker G, Elverhoi A, Marr JG, Mohrig D, Harff PA (2003) Hydroplaning of subaqueous debris flows and glide blocks: analytical solutions and discussion. J Geophys Res 108:2349. doi:10.1029/2001JB001454

Heezen BC, Ericson DB, Ewing M (1954) Further evidence for a turbidity current following the 1929 Grand-Banks earthquake. Deep-Sea Res 1:193-202

Houwing E (1999) Determination of the critical eroson threshold of cohesive sedimentson intertidal mudflats along the Dutch Wadden Sea coast. Estuar Coast Shelf Sci 49:545-555
Ilstad T, Marr JG, Elverhoi A, Harbitz CB (2004a) Laboratory studies of subaqueous debris flows by measurements of pore-fluid presure and total stress. Mar Geol 213:402-414

Ilstad T, Elverhoi A, Issler D, Marr JG (2004b) Subaqueous debris flow behaviour and its dependence on the sand/clay ratio: a laboratory study using particle tracking. Mar Geol 213:415-438

Ilstad T, De Blasio FV, Elverhoi A, Harbitz CB, Engvik L, Longva O, Marr JG (2004c) On the frontal dynamics and morphology of submarine debris flows. Mar Geol 213:481-497

Imran J, Harff P, Parker G (2001) A numerical model of submarine debris flow with graphical user interface. Comput Geosci 27:717-729

Iverson RM (1997) The physics of debris flows. Rev Geophys 35:245-296

Knies J, Jensen HKB, Finne TE, Lepland A, Sather OM (2006) Sediment composition and heavy metal distribution in Barents Sea surface samples: results from Institute of Marine Research 2003 and 2004 cruises. Geological Survey of Norway. ISSN: 0800-3416, $44 \mathrm{pp}$

Kuenen PH, Migliorini CI (1950) Turbidity currents as a cause of graded bedding. J Geol 58:91-127

Laberg JS, Vorren TO (2000) Flow behaviour of the submarine glacigenic debris flows on the Bear Island Trough Mouth Fan, western Barents Sea. Sedimentology 47:1105-1117

Major JJ, Iverson RM (1999) Debris flow deposition: Effects of pore fluid pressure and friction concentrated at flow margins. Geol Soc Am Bull 111:1424-1434

Marr JG, Harff PA, Shanmugam G, Parker G (2001) Experiments on subaqueous sandy gravity flows: the role of clay and water content in flow dynamics and depositional structures. Geol Soc Am Bull 113:1377-1386

Marr JG, Elverhoi A, Harbitz C, Imran J, Harff P (2002) Numerical simulation of mud-rich subaqueous debris flows on the glacially active margins of the Svalbard-Barents Sea. Mar Geol 188:351364

Mitchener H, Torfs H (1996) Erosion of mud/sand mixtures. Coastal Eng 29:1-25

Mohrig D, Marr JG (2003) Constraining the efficiency of turbidity current generation from submarine debris flows and slides using laboratory experiments. Mar Petrol Geol 20:883-899

Mohrig D, Whipple KX, Hondzo M, Ellis C, Parker G (1998) Hydroplaning of subaqueous debris flows. Geol Soc Am Bull 110:387-394

Mohrig D, Elverhoi A, Parker G (1999) Experiments on the relative mobility of muddy subaqueous and subaerial debris flows, and their capacity to remobilize antecedent deposits. Mar Geol 154:117-129

Mulder T, Alexander J (2001) The physical character of subaqueous density flows and their deposits. Sedimentology 48:269-299

Mulder T, Cochonat P (1996) Classification of offshore mass movements. J Sed Res 66:43-57

Nissen SE, Haskell NL, Steiner CT, Coterill KL (1999) Debris flow outrunner blocks, glide tracks, and pressure ridges indentified on the Nigerian Continental slope using 3-D seismic coherency. The Leading Edge, Soc Expl Geophys 18:550-561

Norem H, Locat J, Schieldrop B (1990) An approach to the physics and the modelling of submarine flowslides. Mar Geotechnol 9:93-111

Pagliardi M (2007) Application of PIV technique to the study of subaqueous debris flows. PhD thesis, Università di Pavia, Italia

Parker G (2000) Hydroplaning outrunner blocks from autoacephalated subaqueous debris flows and landslides. Eos Trans AGU 81:OS51D-08

Piper DJW, Aksu AE (1987) The source and origin of the 1929 Grand Banks turbidity-current inferred from sediment budgets. Geo-Mar Lett 7:177-182 
Piper DJW, Normark WR (2009) Processes that initiate turbidity currents and their influence on turbidites: a marine geology perspective. J Sed Res 79:347-362

Piper DJW, Slatt RM (1977) Late Quaternary clay-mineral distribution on eastern continental margin of Canada. Geol Soc Am Bull 88:267-272

Piper DJW, Stow DAV, Normark WR (1984) The Laurentian Fan: Sohm Abyssal Plain. Geo-Mar Lett 3:141-146

Piper DJW, Cochonat P, Morrison ML (1999) The sequence of events around the epicentre of the 1929 Grand Banks earthquake: initiation of debris flows and turbidity current inferred from sidescan sonar. Sedimentology 46:79-97

Pouliquen O (2004) Velocity correlations in dense granular flows. Phys Rev Lett 93:248001

Prior DB, Bornhold BD, Johns MW (1984) Depositional characteristics of a submarine debris flow. J Geol 92:707-727

Remaitre A, Malet JP, Maquaire O, Locat J (2005) Flow behaviour and runout modelling of complex debris flow in a clay-shale basin. Earth Surf Process Land 30:479-488

Schatzmann M, Bezzola GR, Minor HE, Fischer P (2003) The ball measuring system - a new method to determine debris-flow rheology. In: Rickenmann D, Chen CL (eds) Debris-flow hazards mitigation: mechanics, prediction and assessment. Millpress, Rotterdam, p 387

Schlichting H (1980) Boundary layer theory. McGraw-Hill, New York

Sejrup HP, Hjelstuen BO, Dahlgren TKI, Haflidason H, Kuijpers A, Nygård A, Praeg D, Stoker MS, Vorren TO (2005) Pleistocene glacial history of the NW European continental margin. Mar Petrol Geol 22:1111-1129

Si G (2007) Experimentally study the rheology of fine-grained slurries and some numerical simulations of downslopes slurry movements. Master thesis, University of Oslo, Norway, 128 pp
Solheim A, Berg K, Forsberg CF, Bryn P (2005) The Storegga Slide complex: repetitive large scale sliding with similar cause and development. Mar Petrol Geol 22:97-107

Sosio R, Crosta GB, Frattini P (2006) Field observations, rheological testing and numerical modelling of a debris flow event. Earth Surf Process Land 32:290-306

Spinewine B, Capart H, Larcher M, Zech Y (2003) Three-dimensional Voronoi methods for the measurement of near-wall particulate flows. Exp Fluids 34:227-241

Stow DAV (1981) Laurentian Fan: morphology, sediments, processes, and growth pattern. AAPG Bull 65:375-393

Sveen JK, Cowen EA (2004) Quantitative imaging techniques and their application to wavy flows. In: Grue J, Liu PL-F, Pedersen G (eds) PIV and water waves. World Scientific Pub. Co., Singapore, pp 1-50

Talling PJ, Peakall J, Sparks RSJ, Cofaigh CO, Dowdeswell JA, Felix M, Wynn RB, Baas JH, Hogg AJ, Masson DG, Taylor J, Weaver PE (2002) Experimental constrains on shear mixing rates and processes: implications for the dilution of submarine debris flows. In: Dowdeswell JA, Cofaigh CO (eds) Glacier-influenced sedimentation on high-latitude continental margins, vol 203, Special Publications. Geological Society of London, London, pp 89-103

Vorren TO, Laberg JS, Blaume F, Dowdeswell JA, Kenyon NH, Mienert J, Rumohr J, Werner F (1998) The Norwegian Greenland Sea continental margins: morphology and late Quaternary sedimentary processes and environment. Quatern Sci Rev 17:273-302

Young AD (1989) Boundary layers. BSP Professional Books, Oxford

Zreik DA, Khrishnappan BG, Germaine JT, Madsen OS, Ladd CC (1998) Erosional and mechanical strengths of deposited cohesive sediments. J Hydraul Eng ASCE 124:1076-1085 